OPEN ACCESS

Edited by:

Or Kakhlon,

Hadassah Medical Center, Israel

Reviewed by:

Vincenzo Flati,

University of L'Aquila, Italy

Ross F. Collery,

Medical College of Wisconsin,

United States

*Correspondence:

Sovan Sarkar

s.sarkar@bham.ac.uk

Specialty section:

This article was submitted to

Molecular Medicine,

a section of the journal

Frontiers in Cell and Developmental

Biology

Received: 26 June 2019

Accepted: 19 August 2019

Published: 06 September 2019

Citation:

Palhegyi AM, Seranova E

Dimova S, Hoque S and Sarkar S

(2019) Biomedical Implications

of Autophagy in Macromolecule

Storage Disorders.

Front. Cell Dev. Biol. 7:179.

doi: 10.3389/fcell.2019.00179

\section{Biomedical Implications of Autophagy in Macromolecule Storage Disorders}

\author{
Adina Maria Palhegyi, Elena Seranova, Simona Dimova, Sheabul Hoque and \\ Sovan Sarkar*
}

College of Medical and Dental Sciences, Institute of Cancer and Genomic Sciences, Institute of Biomedical Research,

University of Birmingham, Birmingham, United Kingdom

An imbalance between the production and clearance of macromolecules such as proteins, lipids and carbohydrates can lead to a category of diseases broadly known as macromolecule storage disorders. These include, but not limited to, neurodegenerative diseases such as Alzheimer's, Parkinson's and Huntington's disease associated with accumulation of aggregation-prone proteins, Lafora and Pompe disease associated with glycogen accumulation, whilst lipid accumulation is characteristic to NiemannPick disease and Gaucher disease. One of the underlying factors contributing to the build-up of macromolecules in these storage disorders is the intracellular degradation pathway called autophagy. This process is the primary clearance route for unwanted macromolecules, either via bulk non-selective degradation, or selectively via aggrephagy, glycophagy and lipophagy. Since autophagy plays a vital role in maintaining cellular homeostasis, cell viability and human health, malfunction of this process could be detrimental. Indeed, defective autophagy has been reported in a number of macromolecule storage disorders where autophagy is impaired at distinct stages, such as at the level of autophagosome formation, autophagosome maturation or improper lysosomal degradation of the autophagic cargo. Of biomedical relevance, autophagy is regulated by multiple signaling pathways that are amenable to chemical perturbations by small molecules. Induction of autophagy has been shown to improve cell viability and exert beneficial effects in experimental models of various macromolecule storage disorders where the lysosomal functionality is not overtly compromised. In this review, we will discuss the role of autophagy in certain macromolecule storage disorders and highlight the potential therapeutic benefits of autophagy enhancers in these pathological conditions.

Keywords: autophagy, autophagy inducers, selective autophagy, macromolecule storage disorders, neurodegenerative disorders, proteinopathies, lipid storage disorders, glycogen storage disorders

\section{THE REGULATION OF AUTOPHAGY}

Macroautophagy (herein referred to as autophagy) is an essential process for cellular homeostasis and survival of the organism. It selectively removes undesirable macromolecules or damaged organelles which might become toxic if accumulated in the cells, and non-selectively recycles cytosolic materials during starvation to generate energy (Mizushima, 2018). This process starts 
with the formation of isolated membrane structures in the cytoplasm called phagophores. The origin of these membrane structures has been suggested to be from the endoplasmic reticulum (ER), as well as from other sources like mitochondria, Golgi apparatus and plasma membrane (Tooze and Yoshimori, 2010; Yu et al., 2018). The phagophores elongate to form double membrane-bound vesicles called autophagosomes, during which the autophagic cargo is engulfed. The autophagosomes then mature to form the degradative autolysosomes either via a multistep process by initially fusing with the late endosomes to form amphisomes and then with the lysosomes, or by directly fusing with the lysosomes (Nakamura and Yoshimori, 2017). The autophagic cargo is eventually degraded in the autolysosomes by the acidic lysosomal enzymes and the breakdown products are then recycled (Figure 1). These dynamic vesicle fusion events coupled with cargo clearance are collectively defined as autophagic flux.

The classical mechanism regulating autophagy is via the mechanistic target of rapamycin complex 1 (mTORC1) pathway, which negatively regulates this process under nutrient-rich conditions (Kim and Guan, 2015). The levels of growth factors, amino acids and energy status in the cell can also influence autophagy via mTORC1 (Meijer et al., 2015). Physiologically, autophagy is stimulated by starvation via inhibition of mTORC1. Downstream of mTORC1, autophagy initiation is mediated via the ULK1 complex comprising of ULK1, FIP200, ATG13, and ATG101 (Zachari and Ganley, 2017). A positive regulator of autophagy is AMPK, which acts by either inhibiting mTORC1 or by directly inducing autophagy initiation via phosphorylation of ULK1 (Russell et al., 2014; Figure 1). Another downstream target of mTOR that indirectly prevents autophagy is the phosphorylation and cytoplasm sequestration of TFEB, which is a transcription factor mediating the expression of genes related to lysosomal function (Settembre et al., 2013). Apart from mTORC1-dependent regulation, autophagy can also be governed by mTORC1-independent pathways such as increase in the levels of intracellular inositol, $\mathrm{IP}_{3}, \mathrm{Ca}^{2+}$, cAMP and nitric oxide that negatively regulate this process (Sarkar, 2013; Figure 1). Several autophagy-related (ATG) proteins in the autophagic machinery mediate the autophagy initiation steps, such as the ATG12-ATG5-ATG16L1 complex and phosphatidylethanolamine-conjugated LC3-II; the latter remains associated with the autophagosomes throughout their lifespan and acts as a marker of autophagy (Mizushima et al., 2011; Ktistakis and Tooze, 2016). After autophagosome biogenesis, their lysosomal delivery and fusion are mediated by various factors including SNAREs (syntaxin 17 and SNAP29 on autophagosomes, and lysosomal VAMP8), HOPS (homotypic fusion and protein sorting) complex, Rab7, GABARAPs, BRUCE, and Beclin1-interacting partners such as ATG14L and UVRAG (Wang et al., 2016; Reggiori and Ungermann, 2017; Figure 1).

Since autophagy is implicated in myriad human diseases, small molecule autophagy modulators have potential biomedical relevance (Rubinsztein et al., 2012; Sarkar, 2013; Panda et al., 2019). Autophagy can be modulated pharmacologically either via inhibiting mTORC1 or independently of mTORC1. The commonly-used mTOR inhibitors for inducing autophagy are rapamycin (Blommaart et al., 1995) and its ester analog CCI779 (Ravikumar et al., 2004), and Torin 1 (Thoreen et al., 2009). There are several ways of inducing mTOR-independent autophagy, such as with carbamazepine (inositol lowering agent) (Sarkar et al., 2005), trehalose (AMPK activator) (Sarkar et al., 2007a; DeBosch et al., 2016), rilmenidine (cAMP reducing agent) (Williams et al., 2008), verapamil and felodipine $\left(\mathrm{Ca}^{2+}\right.$ channel blockers) (Williams et al., 2008; Siddiqi et al., 2019), amongst others (Figure 1). Additional means include the autophagyinducing peptide, Tat-Beclin 1 (Shoji-Kawata et al., 2013). From a clinical perspective, since mTOR regulates critical cellular processes such as protein translation and cell growth, inducing autophagy independent of mTOR is considered to be a safer approach with lesser side-effects for biomedical applications (Rubinsztein et al., 2012; Sarkar, 2013).

\section{THE ROLE OF AUTOPHAGY IN MACROMOLECULE STORAGE DISORDERS}

An imbalance between the production and clearance of macromolecules, causing their intracellular accumulation, can lead to a category of diseases broadly known as macromolecule storage disorders. Autophagy is a major clearance route for a wide spectrum of macromolecules such as proteins, lipids and carbohydrates, either via non-selective bulk degradation or selectively via aggrephagy (for aggregated proteins), lipophagy (for lipids), and glycophagy (for glycogen) (Stolz et al., 2014; Gatica et al., 2018). Decline in the functionality of autophagy contributes to the build-up of macromolecular materials that could be deleterious to the cells. Indeed, impairment in autophagic flux has been reported in a number of macromolecule storage disorders (Table 1). In these conditions, the defect in autophagy could occur at distinct stages: inhibition in the early stages related to autophagosome formation, or impairment in the late stages involving autophagosome maturation, lysosomal function and autophagic cargo clearance (Figure 2). Since autophagy is a vital homeostatic mechanism, compromised autophagy reduces cell viability and contributes to the disease pathology (Green and Levine, 2014; Jiang and Mizushima, 2014). Of biomedical relevance, pharmacological induction of autophagy has been shown to improve cell viability and exert beneficial effects in transgenic animal models of some macromolecular storage disorders where the lysosomal functionality is not overtly compromised (Table 1; Rubinsztein et al., 2012; Sarkar, 2013; Levine et al., 2015; Seranova et al., 2017; Panda et al., 2019). We will discuss below the role of autophagy in few macromolecular storage disorders and highlight the potential therapeutic benefits of autophagy enhancers in these conditions.

\section{THE ROLE OF AUTOPHAGY IN PROTEINOPATHIES}

Accumulation of aggregated proteins in the brain causes neurodegenerative disorders that are collectively termed 


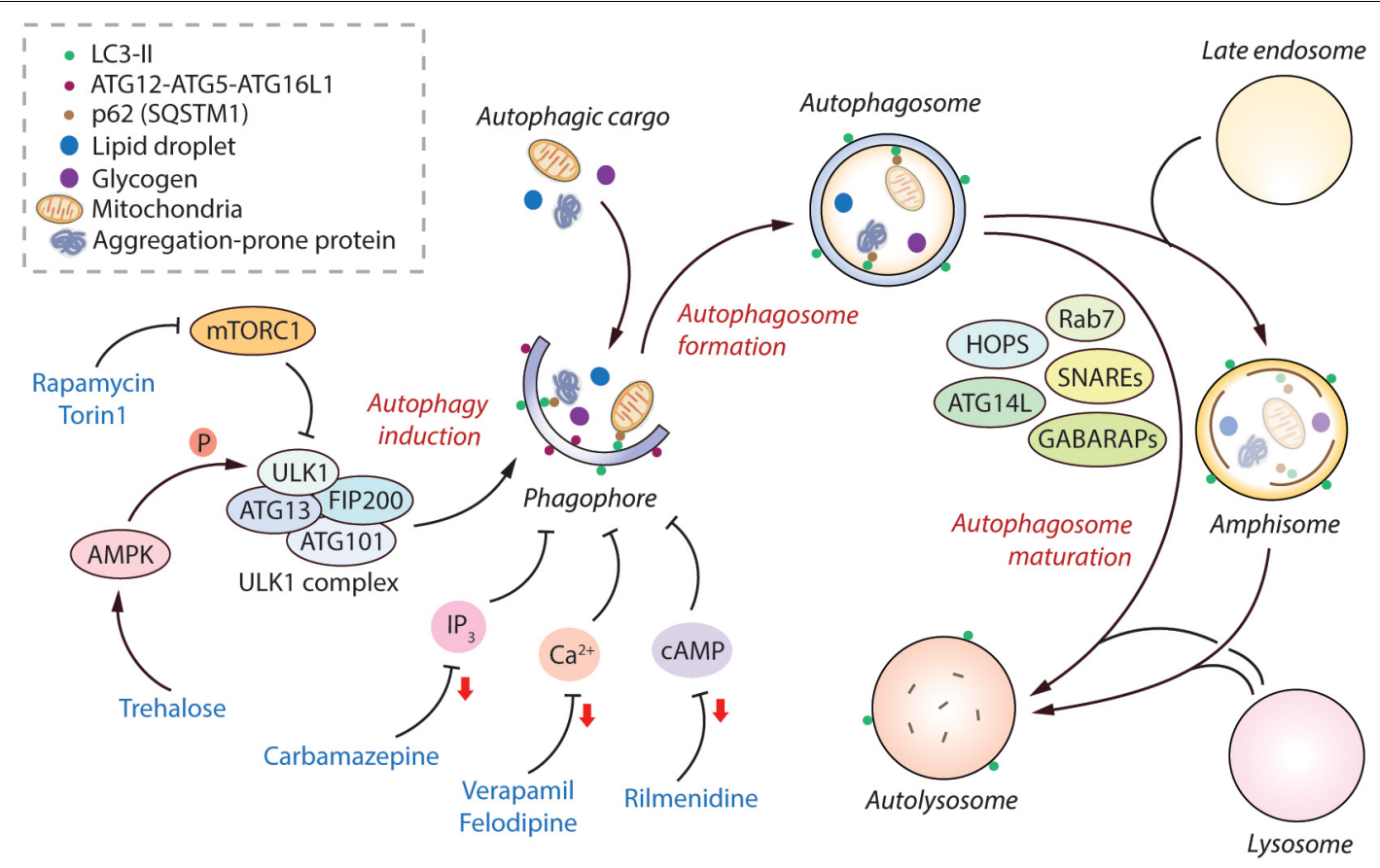

FIGURE 1 | Regulation of the mammalian autophagy pathway. Autophagy initiates by the formation of phagophore that expands and engulfs autophagic cargo to form autophagosome, which then matures to form autolysosome, either by initially fusing with the late endosome to form amphisome and then with the lysosome, or by directly fusing with the lysosome. Selective autophagic cargo includes aggregation-prone proteins, damaged mitochondria, lipid droplets and glycogen, as well as the autophagy receptor protein p62; all of which are degraded in the autolysosome. Several ATG proteins including the ATG12-ATG5-ATG16L1 complex and LC3-II mediate the initiation of autophagy. LC3-II remains on the autophagosome throughout its lifespan and is thus used as a marker for autophagy. The classical regulator of autophagy is mTORC1, which negatively regulates autophagy by inhibiting the ULK1 complex. However, AMPK can positively regulate autophagy by directly phosphorylating ULK1. The mTORC1-independent regulators of autophagy include elevated intracellular levels of IP 3 , Ca ${ }^{2+}$, and cAMP; all of which are autophagy inhibitory signals. Autophagosome maturation in the late stage of autophagy is governed by various factors including SNAREs, HOPS complex, Rab7, GABARAPs, and ATG14L, amongst others. Autophagy can be induced pharmacologically by mTOR inhibitors (rapamycin, torin1), as well as by mTOR-independent inducers such as via AMPK activators (trehalose), and via agents lowering $\mathrm{IP}_{3}$ (carbamazepine), $\mathrm{Ca}^{2+}$ (verapamil, felodipine), and cAMP (rilmenidine) levels (reduction in second messenger molecules indicated by red arrows). Abbreviations - AMPK, $5^{\prime}$ adenosine monophosphate-activated protein kinase; ATG, Autophagy related; $\mathrm{Ca}^{2+}$, Calcium; CAMP, $3^{\prime}, 5^{\prime}$-cyclic adenosine monophosphate; FIP200, FAK family kinase-interacting protein of 200 kDa; GABARAP, $\gamma$-aminobutyric acid receptor-associated protein; HOPS, Homotypic fusion and protein sorting complex; $\mathrm{IP}_{3}$, Inositol 1,4,5-trisphosphate; mTORC1, Mechanistic target of rapamycin complex 1; SNARE, Soluble N-ethylmaleimide-sensitive factor activating protein receptor.

proteinopathies. Autophagy is the primary clearance mechanism for several aggregation-prone proteins, such as amyloid- $\beta$, $\alpha$-synuclein and huntingtin, associated with Alzheimer's, Parkinson's and Huntington's disease, respectively (Nixon, 2013; Menzies et al., 2017); a process termed aggrephagy (Gatica et al., 2018). The misfolded proteins that are targeted for autophagic degradation are ubiquitinated (Grumati and Dikic, 2018). The autophagy cargo receptors, p62 (SQSTM1) (Pankiv et al., 2007), NBR1 (Kirkin et al., 2009), optineurin (Korac et al., 2013), and TOLLIP (Lu et al., 2014), recruit the ubiquitinated cargo to the autophagosomes via their respective ubiquitin-binding domain and LC3-interacting region (LIR), whereas WDFY3 (also known as ALFY) acts as a scaffold for aggrephagy (Filimonenko et al., 2010). Importantly, basal autophagy is critical for maintaining cellular homeostasis in post-mitotic neurons since abrogation of this process in normal mouse brain led to neurodegeneration (Hara et al., 2006; Komatsu et al., 2006); implicating that defective autophagy in neurodegenerative diseases is a major contributing factor. While autophagy dysfunction has been reported in almost all neurodegenerative diseases studied, few common proteinopathies where autophagy induction could be beneficial are discussed below.

\section{Alzheimer's Disease and Tauopathies}

The commonest cause of progressive dementia is Alzheimer's disease $(\mathrm{AD})$, characterized by abnormal metabolism of amyloid precursor protein (APP) that leads to the formation of extracellular senile plaques made of amyloid- $\beta(A \beta)$ (Selkoe and Hardy, 2016). Autophagy has a role in the generation, clearance and secretion of $A \beta$ : $A \beta$ has been suggested to be generated inside autophagosomes containing APP and the enzyme presenilin-1 (PS-1) that cleaves APP into $A \beta ; A \beta$ is degraded via autophagy; and $A \beta$ is possibly secreted to extracellular space via autophagy where it forms plaques (Yu et al., 2005; Nilsson et al., 2013; Tian et al., 2013). In addition, autophagy is dysregulated at multiple stages depending on the gene mutation or the disease agent in AD (Nixon, 2013). Mutations in PS-1 gene, encoding for presenilin-1, impaired lysosomal acidification and function that blocked autophagic flux and prevented autophagosome maturation (Figure 2) because PS1 is required for targeting 
of v-ATPase $\mathrm{V}_{0} \mathrm{a}_{1}$ subunit to the lysosomes for maintaining lysosomal pH (Lee et al., 2010; Wolfe et al., 2013). Indeed, accumulation of autophagosomes was seen in $\mathrm{AD}$ patient brain and in dystrophic neurites of PS1/APP mice (Boland et al., 2008). On the contrary, decrease in beclin-1, which regulates autophagosome formation, was found in the affected areas of $\mathrm{AD}$ patient brain that could be due to activated caspase- 3 cleavage (Pickford et al., 2008; Rohn et al., 2011).

The presence of intracellular neurofibrillary tangles made of hyper-phosphorylated tau, a microtubule-associated protein, is another hallmark of $\mathrm{AD}$ and also for tauopathies including frontotemporal dementias (FTDs) (Spillantini and Goedert, 2013). Mutant tau possibly retards autophagosome-lysosome fusion (Figure 2) by impairing the retrograde axonal transport via the dynein/dynactin complex, as seen in FTD flies and mice (Majid et al., 2014; Butzlaff et al., 2015). In addition, mutant tau colocalized with autophagic vesicles and the aggrephagy receptor protein p62 (Piras et al., 2016), and is likely degraded by autophagy (Berger et al., 2006; Wang et al., 2009).

Chemical or genetic upregulation of autophagy has been shown to be beneficial in transgenic models of $\mathrm{AD}$ and tauopathy. Rapamycin reduced $\mathrm{A} \beta$ plaques and tau tangles and rescued their pathology in APP/Tau/PS1 mutant (3xTg-AD) mice (Caccamo et al., 2010; Majumder et al., 2011), APP/PS1 mutant mice (Jiang et al., 2014a), APP mutant mice (Spilman et al., 2010), APOE4 mutant mice (Lin et al., 2017), FTD mice (Wang et al., 2012), and mutant tau mice (Ozcelik et al., 2013; Jiang et al., 2014b; Siman et al., 2015) and Drosophila (Berger et al., 2006). One of the studies indicated that rapamycin was effective at early stages but not after the plaques and tangles were established (Majumder et al., 2011). Likewise, the mTOR-independent autophagy enhancers, trehalose and carbamazepine, were also effective in clearing these toxic species and improving the disease pathology. Trehalose was beneficial in APP/PS1 mutant mice (Du et al., 2013), APP mutant mice (Portbury et al., 2017) and mutant tau mice (Rodriguez-Navarro et al., 2010; Schaeffer et al., 2012), while carbamazepine in APP/PS1 mice (Tardiff et al., 2013), 3xTg-AD mice (Zhang et al., 2017), and FTD mice (Wang et al., 2012). Additional autophagy-inducing compounds, such as SMER28, latrepirdine and gypenoside XVII (GP-17), were also shown to reduce $A \beta$ levels and improve $A D$ pathology (Tian et al., 2011; Steele et al., 2013; Meng et al., 2016). Genetically, overexpression of beclin-1 or TFEB reduced the levels and pathology of $A \beta$ and tau in APP mutant mice (Pickford et al., 2008) or in mutant APP/PS1 and mutant tau mice (Polito et al., 2014; Xiao et al., 2014), respectively. As a likely consequence of disrupted autophagy, mitophagy is also affected in $\mathrm{AD}$ and is associated with mitochondrial dysfunction and bioenergetics deficits (Kerr et al., 2017); whereas stimulation of mitophagy rescued the $\mathrm{AD}$ pathology in APP/PS1 mutant mice (Fang et al., 2019). Overall, multiple studies have pointed that stimulating autophagy could be beneficial in AD.

\section{Parkinson's Disease}

Parkinson's disease (PD) is the second most common neurodegenerative disorder characterized by motor deficits and cognitive decline (Baizabal-Carvallo and Jankovic, 2016).
The commonly-mutated genes in familial PD encode for $\alpha$-synuclein, PINK1, Parkin, and LRKK2, which have been shown to deregulate autophagy and mitophagy that contribute to the underlying neurodegeneration (Karabiyik et al., 2017). The $\alpha$-synuclein inclusions, also called Lewy bodies that are hallmark of PD, impaired autophagosome maturation without affecting lysosomal function (Tanik et al., 2013). However, overexpression of $\alpha$-synuclein (comparable to its gene multiplication in PD) in cells and transgenic mice suppressed autophagosome formation (Figure 2) by mislocalization of ATG9 (Winslow et al., 2010), and also by cytoplasmic retention of TFEB (Decressac et al., 2013). Similar trafficking defect of ATG9 resulting in autophagy inhibition was seen with mutant VPS35, which causes an autosomal dominant form of PD (Zavodszky et al., 2014). Additionally, mutations or depletion of PD-associated LRRK2, ATP13A2, and STY11 have been suggested to impair autophagy (Bento et al., 2016; Manzoni and Lewis, 2017). The A53T and A30P point mutants of $\alpha$-synuclein, however, mediated their toxic effects by impairing another form of autophagy called chaperone-mediated autophagy (CMA), which involves direct protein translocation across lysosomal membrane (Cuervo et al., 2004; Martinez-Vicente et al., 2008). Apart from the defects in autophagy and CMA in PD, compelling studies demonstrate a direct role of $\mathrm{PD}$-associated mutant proteins in disrupting mitophagy. PINK1 and Parkin, which are commonly mutated in autosomal recessive juvenile $\mathrm{PD}$, normally functions in maintaining mitochondrial quality control (Youle and Narendra, 2011). Damaged mitochondria accumulate PINK1 on its outer membrane that recruits and activates the E3 ubiquitin ligase Parkin, which then ubiquitinates outer mitochondrial membrane proteins to initiate selective mitophagy (Pickrell and Youle, 2015). Pathogenic mutations in PINK1 and Parkin impair mitophagy (Figure 2), which is associated with mitochondrial dysfunction, oxidative stress and mitochondrial DNA mutations (Bender et al., 2006; Geisler et al., 2010; Narendra et al., 2010; Bose and Beal, 2016).

Despite autophagy defects in PD, induction of autophagy could promote autophagic clearance of $\alpha$-synuclein mutants (Webb et al., 2003), and has been shown to be beneficial in toxininduced or transgenic mouse models of PD. Genetic activation of autophagy in $\alpha$-synuclein transgenic mice or rats by Beclin-1 or TFEB overexpression, respectively, decreased $\alpha$-synuclein levels and ameliorated neuropathology (Spencer et al., 2009; Decressac et al., 2013). Pharmacologically, rapamycin rescued disease progression, neuronal loss and mitochondrial dysfunction in MPTP-treated PD mouse models (Malagelada et al., 2010; Liu et al., 2013) and A53T $\alpha$-synuclein transgenic mice (Bai et al., 2015), improved non-motor behavioral changes in 6-OHDA treated PD mouse model (Masini et al., 2018), and prevented dyskinesia in L-DOPA-treated mouse model of Parkinsonism (Santini et al., 2009). An additive effect of rapamycin and trehalose has been demonstrated in inducing autophagy, which was neuroprotective in MPTP-treated PD mice (Pupyshev et al., 2019). Although trehalose could induce autophagy in human and other mammalian cell lines, mouse brain and iPSC-derived neurons, and has been robustly demonstrated to be effective against neurodegeneration by various studies 
TABLE 1 | Defective autophagy in macromolecule storage disorders and therapeutic benefits with autophagy inducers.

\begin{tabular}{llll}
\hline $\begin{array}{l}\text { Mutant } \\
\text { proteins }\end{array}$ & $\begin{array}{l}\text { Autophagy defects and } \\
\text { mechanisms }\end{array}$ & $\begin{array}{l}\text { Autophagy inducers and their mechanisms of } \\
\text { action }\end{array}$ & $\begin{array}{l}\text { Therapeutic benefits in vivo or in iPSC } \\
\text { models }\end{array}$
\end{tabular}

Proteinopathies

\section{Alzheimer's disease (AD) and tauopathy}

PS1 Defective autophagy due to impaired autophagosome maturation; mechanism via impairment in lysosomal acidification due to improper lysosomal targeting of $\mathrm{v}$-ATPase $\mathrm{V}_{0} \mathrm{a}_{1}$ subunit (Lee et al., 2010; Wolfe et al., 2013)

Tau Defective autophagy possibly due to impaired autophagosome maturation; mechanism via disruption of axonal transport (Majid et al., 2014; Butzlaff et al., 2015)
Rapamycin: Induces autophagy by mTORC1 inhibition (Blommaart et al., 1995)

Carbamazepine: Induces mTOR-independent autophagy by lowering inositol and $\mathrm{IP}_{3}$ (Sarkar et al., 2005)

Trehalose: Induces mTOR-independent autophagy via AMPK activation (Sarkar et al., 2007a; DeBosch et al., 2016)

Latrepirdine: Induces autophagy by inhibition of mTORC1 signaling (Steele et al., 2013)

Gypenoside XVII (GP-17): Induces autophagy by TFEB nuclear translocation (Meng et al., 2016)
AD mice (APP/Tau/PS1 mutant) (Caccamo et al., 2010; Majumder et al., 2011), AD mice (APP/PS1 mutant) (Jiang et al., 2014a), AD mice (APP mutant) (Spilman et al., 2010), AD mice (APOE4 mutant) (Lin et al., 2017), FTD mice (TDP-43) (Wang et al., 2012), FTD mice (tau mutant) (Ozcelik et al., 2013; Jiang et al., 2014b; Siman et al., 2015), FTD Drosophila (Berger et al., 2006)

AD mice (APP/PS1 mutant) (Tardiff et al., 2013), AD mice (APP/Tau/PS1 mutant) (Zhang et al., 2017), FTD mice (TDP-43) (Wang et al., 2012)

AD mice (APP/PS1 mutant) (Du et al., 2013), AD mice (APP mutant) (Portbury et al., 2017), FTD mice (tau mutant) (Rodriguez-Navarro et al., 2010; Schaeffer et al., 2012)

AD mice (APP mutant) (Steele et al., 2013)

AD mice (APP/PS1 mutant) (Meng et al., 2016)

\section{Parkinson's disease (PD)}

$\alpha$-syn $\quad \alpha$-syn overexpression causes defective autophagy due to impaired autophagosome formation; mechanism via ATG9 mislocalization (Winslow et al., 2010) and cytoplasmic retention of TFEB (Decressac et al., 2013); whereas A53T and A30P $\alpha$-syn mutants impair CMA (Cuervo et al., 2004; Martinez-Vicente et al., 2008)

Parkin, Defective mitophagy due to impaired PINK1 targeting of damaged mitochondria to autophagosomes (Geisler et al., 2010; Narendra et al., 2010)
Rapamycin: Induces autophagy by mTORC1 inhibition (Blommaart et al., 1995)

Felodipine: Induces mTOR-independent autophagy by lowering cytosolic $\mathrm{Ca}^{2+}$ (Siddiqi et al., 2019)

6-Bio: Induces autophagy by inhibition of mTORC1 signaling (Suresh et al., 2017)

Piperlongumine: Induces autophagy by Bcl2 phosphorylation and Bcl2-Beclin1 dissociation (Liu et al., 2018)
PD mice (A53T $\alpha$-syn) (Bai et al., 2015), PD mice (MPTP treated) (Malagelada et al., 2010; Liu et al., 2013), PD mice (6-OHDA treated) (Masini et al., 2018), PD mice (L-DOPA treated) (Santini et al., 2009)

PD mice (A53T $\alpha$-syn), A53T $\alpha$-syn iPSC-derived neurons (Siddiqi et al., 2019)

PD mice (MPTP treated) (Suresh et al., 2017)

PD mice (rotenone treated) (Liu et al., 2018)

\section{Huntington's disease (HD)}

HTT Defective autophagy due to impaired recognition of autophagic cargo (Martinez-Vicente et al., 2010) and disrupted axonal transport (Wong and Holzbaur, 2014)
Rapamycin, CCl-779: Induces autophagy by mTORC1 inhibition (Blommaart et al., 1995; Ravikumar et al. 2004)

Trehalose: Induces mTOR-independent autophagy via AMPK activation (Sarkar et al., 2007a; DeBosch et al., 2016)

Rilmenidine: Induces mTOR-independent autophagy by lowering cAMP (Williams et al., 2008)
HD mice (HD-N171-82Q) (Ravikumar et al., 2004), HD Drosophila (Ravikumar et al., 2004; Sarkar et al., 2008), HD zebrafish (Williams et al., 2008)

HD mice (HD-ex1-145Q) (Tanaka et al., 2004)a

HD mice (HD-N171-82Q) (Rose et al., 2010) 
TABLE 1 | Continued

\begin{tabular}{|c|c|c|c|}
\hline Mutant proteins & $\begin{array}{l}\text { Autophagy defects and } \\
\text { mechanisms }\end{array}$ & $\begin{array}{l}\text { Autophagy inducers and their mechanism } \\
\text { of action }\end{array}$ & $\begin{array}{l}\text { Therapeutic benefits in vivo or in iPSC } \\
\text { models }\end{array}$ \\
\hline & & $\begin{array}{l}\text { Felodipine: Induces mTOR-independent } \\
\text { autophagy by lowering cytosolic } \mathrm{Ca}^{2+} \text { (Siddiqi } \\
\text { et al., 2019) }\end{array}$ & $\begin{array}{l}\text { HD mice (HD-N171-82Q), HD zebrafish (Siddiqi } \\
\text { et al., 2019) }\end{array}$ \\
\hline & & $\begin{array}{l}\text { SMER28: Induces mTOR-independent } \\
\text { autophagy (Sarkar et al., 2007b); mechanism } \\
\text { not known }\end{array}$ & HD Drosophila (Sarkar et al., 2007b) \\
\hline & & $\begin{array}{l}\text { AUTEN-67, AUTEN-99: Induce autophagy by } \\
\text { MTMR14 inhibition (Billes et al., 2016; Kovacs } \\
\text { et al., 2017) }\end{array}$ & $\begin{array}{l}\text { HD Drosophila (Billes et al., 2016; } \\
\text { Kovacs et al., 2017) }\end{array}$ \\
\hline & & $\begin{array}{l}\text { L-NAME: Induce mTOR-independent } \\
\text { autophagy by NOS inhibition (Sarkar et al., } \\
\text { 2011) }\end{array}$ & $\begin{array}{l}\text { HD Drosophila, HD zebrafish } \\
\text { (Sarkar et al., 2011) }\end{array}$ \\
\hline
\end{tabular}

\section{Lipid storage disorders}

\section{Niemann Pick type $\mathrm{C}$ disease (NPC)}

NPC1 Defective autophagy due to impaired autophagosome maturation; mechanism via failure in SNARE machinery (Sarkar et al., 2013), reduction in SphK activity, and VEGF levels (Lee H. et al., 2014)

NPC2

Defective autophagy possibly due to impaired autophagosome maturation (Guo et al., 2016); mechanism not known
Rapamycin: Induces autophagy by mTORC1 inhibition (Blommaart et al., 1995)

Carbamazepine: Induces mTOR-independent autophagy by lowering inositol and $\mathrm{IP}_{3}$ (Sarkar et al., 2005)

Trehalose: Induces mTOR-independent autophagy via AMPK activation (Sarkar et al., 2007a; DeBosch et al., 2016)

Verapamil: Induces mTOR-independent autophagy by lowering cytosolic $\mathrm{Ca}^{2+}$ (Williams et al., 2008)

BRD5631: Induces mTOR-independent autophagy (Kuo et al., 2015); mechanism not known
NPC1 iPSC-derived neurons and hepatic cells (Maetzel et al., 2014)

NPC1 iPSC-derived neurons and hepatic cells (Maetzel et al., 2014)

NPC1 iPSC-derived neurons (Maetzel et al., 2014)

NPC1 iPSC-derived neurons (Maetzel et al. 2014)

NPC1 iPSC-derived neurons (Kuo et al., 2015)

\section{Gaucher's disease (GD)}

GCase
Defective autophagy possibly due to impaired autophagosome maturation (Sun et al., 2010); mechanism not known but suggested via lysosomal defect (Osellame et al., 2013)

Defective autophagy possibly due to impaired autophagosome maturation; mechanism not clear but suggested via inefficient cathepsin activity (Tatti et al., 2012)
Rapamycin: Induces autophagy by mTORC1 inhibition (Blommaart et al., 1995)
GD Drosophila (Kinghorn et al., 2016)

\section{Fabry disease (FD)}

$\alpha-$ Gal A
Defective autophagy possibly due to impaired autophagosome maturation (Chevrier et al., 2010); mechanism not known 
TABLE 1 | Continued

\begin{tabular}{|c|c|c|c|}
\hline Mutant proteins & $\begin{array}{l}\text { Autophagy defects and } \\
\text { mechanisms }\end{array}$ & $\begin{array}{l}\text { Autophagy inducers and their mechanism } \\
\text { of action }\end{array}$ & $\begin{array}{l}\text { Therapeutic benefits in vivo or in iPSC } \\
\text { models }\end{array}$ \\
\hline \multicolumn{4}{|c|}{ Glycogen storage disorders } \\
\hline Laforin & $\begin{array}{l}\text { Defective autophagy due to impaired } \\
\text { autophagosome formation; mechanism } \\
\text { via mTOR activation (Aguado et al., } \\
\text { 2010) }\end{array}$ & $\begin{array}{l}\text { Metformin: Induces autophagy by AMPK } \\
\text { activation (Buzzai et al., 2007) }\end{array}$ & LD mice $\left(\right.$ Epm2a $\left.{ }^{-/-}\right)($Berthier et al., 2016) \\
\hline Malin & $\begin{array}{l}\text { Defective autophagy due to impaired } \\
\text { autophagosome formation (Criado } \\
\text { et al., 2012); mechanism not known }\end{array}$ & & \\
\hline \multicolumn{4}{|c|}{ Von Gierke's disease (GSDla) } \\
\hline G6PC & $\begin{array}{l}\text { Defective autophagy due to impaired } \\
\text { autophagosome formation; mechanism } \\
\text { via mTOR activation, AMPK inhibition } \\
\text { (Farah et al., 2016), SIRT1 } \\
\text { downregulation (Cho et al., 2017) }\end{array}$ & $\begin{array}{l}\text { Rapamycin: Induces autophagy by mTORC1 } \\
\text { inhibition (Blommaart et al., 1995) } \\
\text { Bezafibrate: PPAR agonist but } \\
\text { autophagy-inducing mechanism not clear } \\
\text { (Waskowicz et al., 2019) }\end{array}$ & $\begin{array}{l}\text { GSDla mice (G6pc } c^{-/-} \text {) (Farah et al., 2016, } \\
\text { 2017); GSDla dogs (Farah et al., 2016) } \\
\text { GSDla mice (G6pc } \\
\text { 2019) }\end{array}$ \\
\hline \multicolumn{4}{|c|}{ Pompe disease (GSDII) } \\
\hline GAA & $\begin{array}{l}\text { Defective autophagy possibly due to } \\
\text { impaired autophagosome maturation } \\
\text { (Raben et al., 2008; Nascimbeni et al., } \\
\text { 2012); mechanism not known }\end{array}$ & $\begin{array}{l}\text { Rapamycin: Induces autophagy by mTORC1 } \\
\text { inhibition (Blommaart et al., 1995) }\end{array}$ & GSDII mice (Gaa-/-) (Ashe et al., 2010) \\
\hline \multicolumn{4}{|c|}{ 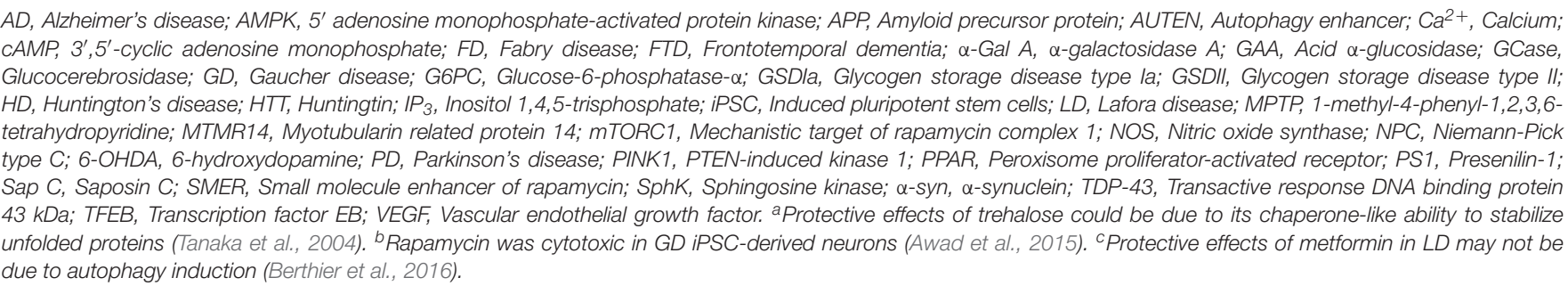 } \\
\hline
\end{tabular}

(Hosseinpour-Moghaddam et al., 2018), a recent report indicated that trehalose and other disaccharides could block autophagy and increase $\alpha$-synuclein aggregation in immortalized human cells or rat cortical neurons (Yoon et al., 2017). Nonetheless, trehalose and several other mTOR-independent autophagy inducers like verapamil, rilmenidine, valproate and calpastatin could enhance the clearance of $\alpha$-synuclein mutants (Webb et al., 2003; Sarkar et al., 2007a; Williams et al., 2008). Another autophagy inducer called 6-Bio, which acts by inhibiting mTORC1 signaling, enhanced $\alpha$-synuclein clearance and ameliorated toxicity in MPTP-treated PD mice (Suresh et al., 2017). Other autophagyinducing compounds like metformin, piperlongumine and nilotinib were also protective in PD mice (Hebron et al., 2014; Liu et al., 2018; Ryu et al., 2018). Interestingly, retinoic acid derivatives such as AR7, GR1 and GR2 were shown to activate CMA for lowering $\alpha$-synuclein levels and improving cell viability in a PD cell model expressing $\alpha$-synuclein (Anguiano et al., 2013).

\section{Huntington's Disease}

Huntington's disease (HD) is a monogenic, autosomal dominant, neurodegenerative disorder characterized by motor and cognitive deficits. HD is caused by expansion of CAG repeats in HTT gene, resulting in polyglutamine-expanded mutant huntingtin protein that is aggregation-prone, cytotoxic (Zoghbi and Orr, 2000), and is predominantly degraded by autophagy (Ravikumar et al., 2002). Despite accumulation of autophagosomes in HD models (Kegel et al., 2000; Petersen et al., 2001), defective autophagy in $\mathrm{HD}$ is attributed to failure in autophagic cargo recognition. Mutant huntingtin impairs the recognition and recruitment of autophagic cargo by autophagosomes (Martinez-Vicente et al., 2010; Figure 2), whereas wild-type huntingtin acts as a scaffold for recruiting autophagic proteins during selective autophagy such as aggrephagy and mitophagy (Ochaba et al., 2014; Rui et al., 2015). In addition, mutant huntingtin was also reported to perturb the axonal transport of autophagosomes that affected cargo degradation (Wong and Holzbaur, 2014), which was also retarded by decreased dynein function that prevented the clearance of aggregation-prone proteins and augmented toxicity (Ravikumar et al., 2005). Although mutant huntingtin is an established autophagy substrate (Sarkar and Rubinsztein, 2008), a recent study suggested that the conformation of mutant huntingtin dictates its ability to be cleared by autophagy. A toxic 


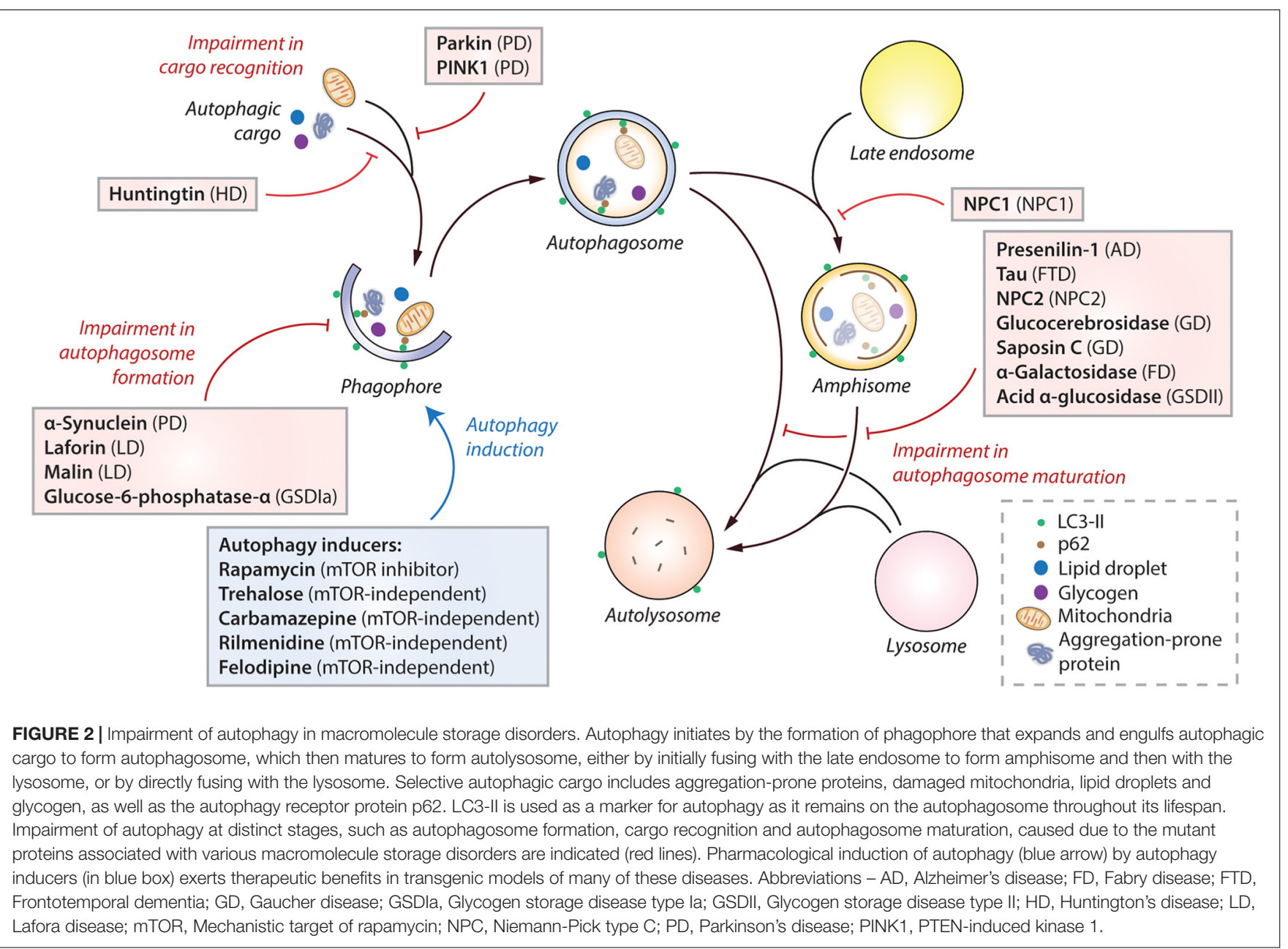

form of mutant huntingtin, recognized by the polyglutamine antibody $3 \mathrm{~B} 5 \mathrm{H} 10$, was found to lack Lys63 polyubiquitination that is essential to interact with p62/SQSTM1 for selective autophagy (Fu et al., 2017).

Nonetheless, pharmacological stimulation of autophagy enhances the clearance of mutant huntingtin preferentially over its wild-type counterpart (Ravikumar et al., 2002), and the beneficial effects of autophagy induction are robustly demonstrated in cell, Drosophila, zebrafish and mouse models of HD (Sarkar et al., 2009). Amelioration of disease phenotypes in HD mice with autophagy-inducing compounds has been shown with rapamycin (Ravikumar et al., 2004), trehalose (Tanaka et al., 2004), rilmenidine (Rose et al., 2010), calpastatin (Menzies et al., 2015), and recently, with the anti-hypertensive drug felodipine at pharmacokinetics similar to its conventional application in humans (Siddiqi et al., 2019); and also in HD fly models with SMERs (Sarkar et al., 2007b), L-NAME (Sarkar et al., 2011), AUTEN-67 (Billes et al., 2016), AUTEN-99 (Kovacs et al., 2017), verapamil and valproate (Williams et al., 2008). A combination strategy for maximal stimulation of autophagy via mTOR inhibition and mTOR-independent routes was more effective in $\mathrm{HD}$ Drosophila than either approach (Sarkar et al., 2008). Overall, modulation of autophagy presents an attractive treatment option for HD patients.

\section{THE ROLE OF AUTOPHAGY IN GLYCOGEN STORAGE DISORDERS}

The selective clearance of carbohydrates such as glycogen via autophagy is termed glycophagy, which plays a crucial role in glucose homeostasis (Zirin et al., 2013; Zhao et al., 2018). The starch-binding domain-containing protein 1 (STBD1) has been identified as the receptor for selective glycophagy. STBD1 captures glycogen particles to autophagosomes by interacting with glycogen via its glycan-binding domain and with GABARAPL1 via its LIR motif (Jiang et al., 2011; Zhu et al., 2014). Improper glycophagy in glycogen storage disorders may contribute to the disease pathology (Zhao et al., 2018).

\section{Lafora Disease}

Lafora disease (LD) is an autosomal recessive myoclonus epilepsy characterized by neurodegeneration and intracellular inclusions of poorly-branched glycogen deposits called Lafora bodies (Nitschke et al., 2018). The commonly-mutated genes are EPM2A 
and $E P M 2 B$ that encode laforin (phosphatase) and malin (E3 ubiquitin ligase), respectively, which together functions in the ubiquitin-proteasome system for promoting misfolded protein clearance (Garyali et al., 2009). Knockout of these genes in mice inhibited autophagosome formation (Figure 2), suggesting impairment of autophagy in LD that was also observed in patient fibroblasts (Aguado et al., 2010; Criado et al., 2012; Duran et al., 2014). Mutant laforin suppressed autophagy by activating mTOR, whereas overexpression of wild-type laforin induced autophagy by inhibiting mTOR (Aguado et al., 2010). Activation of mTOR in laforin-deficient cells further activated serum/glucocorticoid-induced kinase 1 (SGK1), and suppression of SGK1 activity could lower glycogen accumulation, inhibited mTOR and rescued the autophagy defect (Singh et al., 2013). Defective autophagic flux could lead to inefficient glycophagy and build-up of Lafora bodies that have neurotoxic effects (Duran et al., 2014); additionally, was also associated with impaired mitophagy, increased mitochondrial fragmentation and ROS production, and decreased ATP levels in laforin- and malindeficient cells (Roma-Mateo et al., 2015; Upadhyay et al., 2017; Lahuerta et al., 2018).

Expression of the wild-type or phosphatase-inactive mutant of laforin corrected glycogen branching, restored functional autophagy and reduced LB formation in Epm $2 a^{-/-}$mice (Gayarre et al., 2014), suggesting that abnormal glycogen accumulation in $\mathrm{LD}$ is likely via malfunction of cellular proteostasis and not due to glycogen dephosphorylation by laforin. These studies implicate defective autophagy in the pathogenesis of LD. Although a study has shown that metformin (AMPK activator and autophagy inducer) reduced LBs and neurodegeneration in Epm $2 a^{-/-}$mice, the beneficial effects of this compound were not attributed to autophagy induction because it did not affect autophagy in vivo (Berthier et al., 2016). Nonetheless, since autophagy induction could have potential benefits by facilitating LB clearance and delaying neurodegeneration, further drug trials in $\mathrm{LD}$ mice are required to demonstrate whether this would be a therapeutic strategy.

\section{Pompe Disease}

Pompe disease, also known as glycogen storage disease type II (GSDII), is an autosomal recessive glycogen storage disorder that affects muscle and nerve cells, and cause muscle weakness. GSDII is caused by mutations in the gene encoding for acid $\alpha$-glucosidase (GAA), a lysosomal glycogen hydrolase. GAA normally degrades glycogen, but its mutations lead to glycogen accumulation in the lysosomes especially in cardiac and skeletal muscles (Raben et al., 2002). Accumulation of autophagosomes and autophagy substrates as well as vacuolization, enlarged lysosomes and improper lysosomal acidification were found in the myotubes of patients and primary myoblasts of Gaa-deficient mice (Fukuda et al., 2006b; Raben et al., 2008; Takikita et al., 2009; Nascimbeni et al., 2012); implicating a block in autophagy at late stage (Figure 2). This is associated with inefficient mitophagy and impaired mitochondrial function (Lim et al., 2015). Moreover, since autophagy has been shown to influence GAA maturation and glycogen clearance (Nascimbeni et al., 2012; Zirin et al., 2013; Zhao et al., 2018), dysfunctional autophagy probably contributes to the pathogenesis of GSDII. In addition, mTOR activity was suppressed in the myotubes of Gaa-deficient mice where mTOR remained on the lysosomes even during starvation; and these effects including autophagosome accumulation were rescued by genetic reactivation of mTOR (Lim et al., 2017).

A common treatment for GSDII is the enzyme replacement therapy (ERT) (Desnick and Schuchman, 2012), but its efficiency is variable and temporary that has been suggested to depend on the degree of autophagy dysfunction. This is because the trafficking and processing of the recombinant human GAA seems to be affected by autophagy (Fukuda et al., 2006a; Nascimbeni et al., 2015). Autophagy activation by itself, either genetically via TFEB or TFE3 overexpression or pharmacologically with rapamycin, reduced glycogen and autophagosome load by promoting autophagosome maturation and lysosomal exocytosis in the myotubes of GSDII mice and patients and in iPSCderived skeletal muscles (Ashe et al., 2010; Medina et al., 2011; Nascimbeni et al., 2012; Spampanato et al., 2013; Martina et al., 2014; Sato et al., 2016). Therefore, combination of ERT with autophagy induction may be more effective. Indeed, combining rapamycin or CCI-779 treatment with ERT reduced muscle glycogen levels in GSDII mice more than either treatment alone (Ashe et al., 2010). These studies highlight the therapeutic importance of autophagy in GSDII.

\section{Von Gierke's Disease}

Von Gierke's disease, also known as glycogen storage disorder type Ia (GSDIa), is an autosomal recessive disorder associated with hepatomegaly and kidney failure with symptoms including hypoglycemia, lactic acidosis and hyperlipidemia. GSDIa is characterized by glucose-6-phosphatase- $\alpha$ (G6PC) deficiency and decreased ability of the liver and kidney to break down glycogen into glucose that causes build-up of glycogen and triglycerides (Chou et al., 2010). Autophagy has been shown to be suppressed (Figure 2) in hepatic cell and mouse $\left(G 6 p c^{-/-}\right)$models of GSDIa possibly via activation of mTOR, inhibition of AMPK and reduced nuclear localization of TFEB (Farah et al., 2016). Likewise, increased acetyl coenzyme A in GSDIa could also have the same effect (Chou et al., 2010; Marino et al., 2014). Additionally, G6pc-/- mice also exhibited defective autophagy in the liver via downregulation of sirtuin-1 (SIRT1) (Cho et al., 2017), an enzyme which stimulates autophagy directly by deacetylation of ATG proteins and indirectly by deacetylation and activation of FoxO transcription factors that transactivate autophagy genes ( $\mathrm{Ng}$ and Tang, 2013). Indeed, impaired autophagy in $G 6 p c^{-/-}$mouse liver was attributed to increased acetylation of Atg5 and Atg7, decreased Atg5-Atg12 conjugation and reduced autophagosome formation (Cho et al., 2017).

Genetically, replacement of G6pc via recombinant adenoassociated virus (rAAV) vector improved hepatic glucose homeostasis and autophagic flux, and also restored SIRT1-FoxO signaling in $G 6 p c^{-/-}$mice; although rAAV-mediated hepatic SIRT1 expression only rescued the autophagy abnormalities but not the metabolic defects (Cho et al., 2017). Pharmacologically, inducing autophagy with rapamycin reduced hepatic triglyceride, glycogen content and necrosis in the liver of $G 6 p c^{-/-}$mice, diminished liver size and markers of liver damage in GSDIa 
dogs that were homozygous for an inactivating mutation in G6pc (Farah et al., 2016), and decreased ER stress in the kidney of $G 6 p c^{-/-}$mice (Farah et al., 2017). In adult (older) mice, however, rapamycin could not rescue the defective autophagic flux in the liver but only marginally increased autophagosome formation (Cho et al., 2017). This study suggested that the differences between these two responses to rapamycin in the liver is thought to be due to the age of the mice as the hepatic gene expression regulated by mTOR differs depending on developmental stages and age (Boylan et al., 2015; Cho et al., 2017). Furthermore, a pan-PPAR (peroxisome proliferatoractivated receptor) agonist called bezafibrate, a lipid-lowering drug used for treating hyperlipidemia, was shown to reduce liver triglyceride and glycogen levels, induce mitochondrial biogenesis and improve autophagic flux in $G 6 p c^{-/-}$mice (Waskowicz et al., 2019). Since PPAR $\alpha$ agonists such as Wy-14 643 and GW7647 could stimulate hepatic lipophagy and attenuate liver injury in mice and patients with acute liver failure (Jiao et al., 2014; Lee J.M. et al., 2014), modulation of PPAR $\alpha$ (a nutrient-sensing nuclear receptor) for inducing hepatic autophagy might represent a potential therapeutic target for the treatment of GSDIa.

\section{THE ROLE OF AUTOPHAGY IN LIPID STORAGE DISORDERS}

Autophagy is a major clearance route for intracellular lipids via a process termed lipophagy. This is evident from genetic ablation of autophagy in mice that increased triglyceride content and lipid droplets (Singh et al., 2009). However, the exact mechanism of selectively targeting the lipid droplets for autophagic degradation is not clear. In lipid storage disorders, malfunction of autophagy could thus contribute to the disease pathology (Ward et al., 2016).

\section{Gaucher Disease}

Gaucher disease (GD) is an autosomal recessive lysosomal storage disorder associated with neurological damage and hepatosplenomegaly. GD is characterized by mutations in GBA1 gene encoding for glucocerebrosidase (GCase), an enzyme that hydrolyses glucosylceramide; and in rare cases by mutations in PSAP gene that leads to deficiency of the GCase activator, saposin C (Stirnemann et al., 2017). Lysosomal accumulation of glucosylceramide and glucosylsphingosine in GD is thought to impair autophagy in the late stages (Figure 2). Indeed, a block in autophagic flux associated with accumulation of autophagy substrates, ubiquitinated proteins, autophagosomes, and inefficient cathepsin activity, was seen in mice, flies, patient fibroblasts and iPSC-derived neuronal models of GD with GCase or saposin C deficiency (Sun et al., 2010; Vaccaro et al., 2010; Tatti et al., 2012; Osellame et al., 2013; Farfel-Becker et al., 2014; Awad et al., 2015; de la Mata et al., 2015). Defective mitophagy, mitochondrial dysfunction and oxidative stress were also found in GD that are likely consequences of impaired autophagy (Cleeter et al., 2013; Osellame et al., 2013; de la Mata et al., 2015; Kinghorn et al., 2016; Li et al., 2019).
Interestingly, mutations in GBA1 gene could induce neurodegeneration and correlated with increased risk of developing Parkinson's disease (PD) (Sidransky et al., 2009; Farfel-Becker et al., 2014). This is because GCase and $\alpha$-synuclein form a pathogenic loop wherein GCase deficiency (in GD) caused autophagic dysfunction and $\alpha$-synuclein accumulation whereas overexpression of $\alpha$-synuclein (in idiopathic PD) could disrupt GCase trafficking and activity (Mazzulli et al., 2011; Schondorf et al., 2014; Du et al., 2015; Magalhaes et al., 2016). In a Drosophila model of neuronopathic GD, decreased mTOR activity and upregulation of the fly ortholog of mammalian TFEB was observed, which is thought to work as a compensatory mechanism for overcoming the autophagic block (Kinghorn et al., 2016). Further inhibition of mTOR with rapamycin extended the life span and rescued the disease pathogenesis in GD flies (Kinghorn et al., 2016). Contrary to these fly data, GD patient-specific iPSC-derived neurons exhibited downregulation of TFEB and lysosomal genes, where rapamycin treatment caused cell death (Awad et al., 2015). However, recombinant GCase rescued the defective autophagy and lysosomal depletion phenotypes in these disease-affected neurons; effects that were augmented by TFEB overexpression but not on its own (Awad et al., 2015). It is plausible that induction of autophagy in the presence of lysosomal dysfunction might be detrimental in disease-affected neurons, however, various mTOR-independent autophagy inducers need to be assessed in GD neurons to make this conclusion.

\section{Niemann-Pick Type C Disease}

Niemann-Pick type C (NPC) disease is an autosomal recessive, lysosomal storage disorder associated with severe neurodegeneration and hepatosplenomegaly. It is caused by mutations in NPC1 gene (95\% cases; NPC1 disease) or NPC2 gene (5\% cases; NPC2 disease) (Vanier, 2010). NPC1 (lysosomal cholesterol transporter) and NPC2 (lysosomal glycoprotein) proteins are suggested to facilitate cholesterol transport from the late endosomal/lysosomal compartments, and their mutations cause accumulation of unesterified cholesterol in the brain and other tissues (Karten et al., 2009; Kwon et al., 2009). In NPC1 and NPC2 disease, a block in autophagic flux occurs due to impaired autophagosome maturation (Figure 2) that results in build-up of autophagosomes and autophagic cargo (Sarkar et al., 2013; Lee H. et al., 2014; Guo et al., 2016) including defective mitophagy and mitochondrial function (Ordonez et al., 2012; Guo et al., 2016); although lysosomal function was not overtly compromised (Sarkar et al., 2013). Various mechanisms underlying autophagy defect in NPC1 disease have been described using mutant mice, patient fibroblasts and iPSCderived neuronal models. These include failure in the SNARE machinery between autophagosomal Syntaxin-17 and late endosomal/lysosomal VAMP8 to prevent vesicle fusion (Fraldi et al., 2010; Sarkar et al., 2013), accumulation of sphingosine due to reduced sphingosine kinase activity and vascular endothelial growth factor (VEGF) levels (Lee H. et al., 2014), and depletion of lysosomal $\mathrm{Ca}^{2+}$ stores (Lloyd-Evans et al., 2008) that could affect autophagy via calcineurin or calpain (Williams et al., 2008; Medina et al., 2015). Interestingly, the most common NPC1 
mutant (I1061T) is shown to be selectively degraded via ER autophagy (ER-phagy) and ER-associated protein degradation (ERAD) (Schultz et al., 2018).

Of therapeutic relevance, autophagy inducers such as rapamycin and carbamazepine rescued the autophagy defect and improved cell viability in NPC1 iPSC-derived neuronal and hepatic cells, whereas trehalose, verapamil and BRD5631 were effective only in neurons (Maetzel et al., 2014; Kuo et al., 2015). Although the multi-step route of autophagosome maturation was impaired in NPC1 disease, autophagy induction restored functional autophagic flux via the bypass mechanism enabling direct autophagosome-lysosome fusion; but this did not reduce the cellular cholesterol load (Sarkar et al., 2013). Strikingly, cholesterol-depleting agents like 2-hydroxypropyl$\beta$-cyclodextrin, which has advanced in clinical trials, exhibited further impairment in autophagic flux, neurotoxic effects and adverse effects in animals (Peake and Vance, 2012; Sarkar et al., 2013; Vite et al., 2015). However, $\beta$-cyclodextrin derivatives such as methyl- $\beta$-cyclodextrin or $\beta$-cyclodextrin-threaded biocleavable polyrotaxanes could rescue the autophagy defect and enhance cholesterol clearance in NPC1 cells (Tamura and Yui, 2015; Dai et al., 2017); although the effect on autophagy may not be their primary roles. Future directions may include efficacy studies of combination treatment involving autophagy inducer and a low-dose of cholesterol-depleting agent in mouse models.

\section{Fabry Disease}

Fabry disease (FD) is a X-linked lysosomal storage disorder characterized by mutations in the GLA gene on the $\mathrm{X}$ chromosome encoding the lysosomal enzyme, $\alpha$-galactosidase A ( $\alpha-G a l$ A). FD is associated with impaired glycosphingolipid metabolism, lysosomal accumulation of a particular fat called globotriaosylceramide (Gb3) and multi-organ dysfunction (Germain, 2010). Autophagic flux is impaired in FD possibly due to defective autophagosome maturation (Figure 2), as evident from accumulation of autophagosomes, lysosomes and autophagy substrates in patient fibroblasts, human podocyte model and $\alpha$-Gal A deficient mice (Chevrier et al., 2010; Liebau et al., 2013; Nelson et al., 2014). However, buildup of autophagosomes may also occur due to increased biogenesis because FD podocytes displayed inhibition of mTOR and increased expression of autophagy initiation genes, BECN1 and GABARAP (Liebau et al., 2013; Braun et al., 2019). Autophagy dysfunction has been suggested to contribute to the neuropathological manifestations of FD, and also to podocyte damage in the kidneys resulting in endstage renal disease that is a common cause of death in FD (Liebau et al., 2013; Nelson et al., 2014). In female patient fibroblasts, the disease severity correlated with the extent of impaired autophagy (Yanagisawa et al., 2019). The autophagy dysfunction is thought to interfere with the efficiency of ERT in FD podocytes (Chevrier et al., 2010); a phenomenon also reported in Pompe disease. Therefore, ERT coupled with induction of autophagy could be evaluated to improve the disease outcome.

\section{CONCLUDING REMARKS}

Autophagy is responsible for the maintenance of cellular homeostasis, and the functionality of this vital process is impaired in different ways in myriad macromolecule storage disorders associated with accumulation of aggregation-prone proteins, carbohydrates and lipids. Beyond the pathologies outlined in this review, autophagy has been implicated in several other macromolecule storage disorders including amyotrophic lateral sclerosis and polyglutamine diseases associated with build-up of aggregation-prone proteins (Menzies et al., 2017), and neuronal ceroid lipofuscinosis associated with build-up of lipofuscin that are lipopigment materials made up of lipids and proteins (Seranova et al., 2017). Defective autophagy reported in many such conditions has been suggested to contribute to the disease pathology, whereas in certain instances, stimulation of autophagy is beneficial which could reduce the macromolecular burden and prevent cytotoxicity. Autophagy inducing-compounds have been shown to attenuate the disease phenotype in various cell, fly and mouse models of these diseases where the lysosomal degradative capability if not overtly compromised. Modulation of autophagy by small molecules might thus represent an attractive therapeutic strategy in macromolecule storage disorders, but disease-specific treatments must be thoroughly researched because some of the conditions might require a combination of autophagy inducer and conventional therapy.

\section{AUTHOR CONTRIBUTIONS}

AP and SS wrote the overall manuscript. ES, SD, and SH reviewed and contributed to the manuscript. AP, SD, and SS made the table. $\mathrm{AP}, \mathrm{SH}$, and SS made the figures.

\section{FUNDING}

SS has been funded by Wellcome Trust Seed Award (109626/Z/15/Z), UKIERI (UK-India Education and Research Initiative) DST Thematic Partnership Award (2016-170087), Wellcome Trust ISSF (1516ISSFFEL10), FAPESPBirmingham-Nottingham Strategic Collaboration Fund, and Birmingham Fellowship from the University of Birmingham, United Kingdom. SH is funded by MRC IMPACT DTP Studentship. SS is also a Former Fellow for life at Hughes Hall, University of Cambridge, United Kingdom.

\section{ACKNOWLEDGMENTS}

We thank the funding agencies for supporting our research. 


\section{REFERENCES}

Aguado, C., Sarkar, S., Korolchuk, V. I., Criado, O., Vernia, S., Boya, P., et al. (2010). Laforin, the most common protein mutated in Lafora disease, regulates autophagy. Hum. Mol. Genet. 19, 2867-2876. doi: 10.1093/hmg/ddq190

Anguiano, J., Garner, T. P., Mahalingam, M., Das, B. C., Gavathiotis, E., and Cuervo, A. M. (2013). Chemical modulation of chaperone-mediated autophagy by retinoic acid derivatives. Nat. Chem. Biol. 9, 374-382. doi: 10.1038/ nchembio. 1230

Ashe, K. M., Taylor, K. M., Chu, Q., Meyers, E., Ellis, A., Jingozyan, V., et al. (2010). Inhibition of glycogen biosynthesis via mTORC1 suppression as an adjunct therapy for Pompe disease. Mol. Genet. Metab. 100, 309-315. doi: 10.1016/j. ymgme.2010.05.001

Awad, O., Sarkar, C., Panicker, L. M., Miller, D., Zeng, X., Sgambato, J. A., et al. (2015). Altered TFEB-mediated lysosomal biogenesis in Gaucher disease iPSCderived neuronal cells. Hum. Mol. Genet. 24, 5775-5788. doi: 10.1093/hmg/ ddv297

Bai, X., Wey, M. C., Fernandez, E., Hart, M. J., Gelfond, J., Bokov, A. F., et al. (2015). Rapamycin improves motor function, reduces 4-hydroxynonenal adducted protein in brain, and attenuates synaptic injury in a mouse model of synucleinopathy. Pathobiol. Aging Age Relat. Dis. 5:28743. doi: 10.3402/pba.v5. 28743

Baizabal-Carvallo, J. F., and Jankovic, J. (2016). Parkinsonism, movement disorders and genetics in frontotemporal dementia. Nat. Rev. Neurol. 12, 175-185. doi: 10.1038/nrneurol.2016.14

Bender, A., Krishnan, K. J., Morris, C. M., Taylor, G. A., Reeve, A. K., Perry, R. H., et al. (2006). High levels of mitochondrial DNA deletions in substantia nigra neurons in aging and Parkinson disease. Nat. Genet. 38, 515-517. doi: $10.1038 /$ ng1769

Bento, C. F., Ashkenazi, A., Jimenez-Sanchez, M., and Rubinsztein, D. C. (2016). The Parkinson's disease-associated genes ATP13A2 and SYT11 regulate autophagy via a common pathway. Nat. Commun. 7:11803. doi: 10.1038/ ncomms 11803

Berger, Z., Ravikumar, B., Menzies, F. M., Oroz, L. G., Underwood, B. R., Pangalos, M. N., et al. (2006). Rapamycin alleviates toxicity of different aggregate-prone proteins. Hum. Mol. Genet. 15, 433-442. doi: 10.1093/hmg/ddi458

Berthier, A., Paya, M., Garcia-Cabrero, A. M., Ballester, M. I., Heredia, M., Serratosa, J. M., et al. (2016). Pharmacological interventions to ameliorate neuropathological symptoms in a mouse model of Lafora disease. Mol. Neurobiol. 53, 1296-1309. doi: 10.1007/s12035-015-9091-8

Billes, V., Kovacs, T., Hotzi, B., Manzeger, A., Tagscherer, K., Komlos, M., et al. (2016). AUTEN-67 (autophagy enhancer-67) hampers the progression of neurodegenerative symptoms in a Drosophila model of Huntington's disease. J. Huntingtons Dis. 5, 133-147. doi: 10.3233/JHD-150180

Blommaart, E. F., Luiken, J. J., Blommaart, P. J., van Woerkom, G. M., and Meijer, A. J. (1995). Phosphorylation of ribosomal protein S6 is inhibitory for autophagy in isolated rat hepatocytes. J. Biol. Chem. 270, 2320-2326. doi: $10.1074 /$ jbc.270.5.2320

Boland, B., Kumar, A., Lee, S., Platt, F. M., Wegiel, J., Yu, W. H., et al. (2008). Autophagy induction and autophagosome clearance in neurons: relationship to autophagic pathology in Alzheimer's disease. J. Neurosci. 28, 6926-6937. doi: 10.1523/JNEUROSCI.0800-08.2008

Bose, A., and Beal, M. F. (2016). Mitochondrial dysfunction in Parkinson's disease. J. Neurochem. 139(Suppl. 1), 216-231. doi: 10.1111/jnc.13731

Boylan, J. M., Sanders, J. A., Neretti, N., and Gruppuso, P. A. (2015). Profiling of the fetal and adult rat liver transcriptome and translatome reveals discordant regulation by the mechanistic target of rapamycin (mTOR). Am. J. Physiol. Regul. Integr. Comp. Physiol. 309, R22-R35. doi: 10.1152/ajpregu.00114.2015

Braun, F., Blomberg, L., Brodesser, S., Liebau, M. C., Schermer, B., Benzing, T., et al. (2019). Enzyme replacement therapy clears Gb3 deposits from a podocyte cell culture model of Fabry disease but fails to restore altered cellular signaling. Cell. Physiol. Biochem. 52, 1139-1150. doi: 10.33594/000000077

Butzlaff, M., Hannan, S. B., Karsten, P., Lenz, S., Ng, J., Vossfeldt, H., et al. (2015). Impaired retrograde transport by the Dynein/Dynactin complex contributes to Tau-induced toxicity. Hum. Mol. Genet. 24, 3623-3637. doi: 10.1093/hmg/ ddv107

Buzzai, M., Jones, R. G., Amaravadi, R. K., Lum, J. J., DeBerardinis, R. J., Zhao, F., et al. (2007). Systemic treatment with the antidiabetic drug metformin selectively impairs p53-deficient tumor cell growth. Cancer Res. 67, 6745-6752. doi: 10.1158/0008-5472.can-06- 4447

Caccamo, A., Majumder, S., Richardson, A., Strong, R., and Oddo, S. (2010). Molecular interplay between mammalian target of rapamycin (mTOR), amyloid-beta, and Tau: effects on cognitive impairments. J. Biol. Chem. 285, 13107-13120. doi: 10.1074/jbc.M110.100420

Chevrier, M., Brakch, N., Celine, L., Genty, D., Ramdani, Y., Moll, S., et al. (2010). Autophagosome maturation is impaired in Fabry disease. Autophagy 6, 589-599. doi: 10.4161/auto.6.5.11943

Cho, J. H., Kim, G. Y., Pan, C. J., Anduaga, J., Choi, E. J., Mansfield, B. C., et al. (2017). Downregulation of SIRT1 signaling underlies hepatic autophagy impairment in glycogen storage disease type Ia. PLoS Genet. 13:e1006819. doi: 10.1371/journal.pgen.1006819

Chou, J. Y., Jun, H. S., and Mansfield, B. C. (2010). Glycogen storage disease type I and G6Pase-beta deficiency: etiology and therapy. Nat. Rev. Endocrinol. 6, 676-688. doi: 10.1038/nrendo.2010.189

Cleeter, M. W., Chau, K. Y., Gluck, C., Mehta, A., Hughes, D. A., Duchen, M., et al. (2013). Glucocerebrosidase inhibition causes mitochondrial dysfunction and free radical damage. Neurochem. Int. 62, 1-7. doi: 10.1016/j.neuint.2012. 10.010

Criado, O., Aguado, C., Gayarre, J., Duran-Trio, L., Garcia-Cabrero, A. M., Vernia, S., et al. (2012). Lafora bodies and neurological defects in malin-deficient mice correlate with impaired autophagy. Hum. Mol. Genet. 21, 1521-1533. doi: 10. 1093/hmg/ddr590

Cuervo, A. M., Stefanis, L., Fredenburg, R., Lansbury, P. T., and Sulzer, D. (2004). Impaired degradation of mutant alpha-synuclein by chaperonemediated autophagy. Science 305, 1292-1295. doi: 10.1126/science.110 1738

Dai, S., Dulcey, A. E., Hu, X., Wassif, C. A., Porter, F. D., Austin, C. P., et al. (2017) Methyl-beta-cyclodextrin restores impaired autophagy flux in Niemann-Pick C1-deficient cells through activation of AMPK. Autophagy 13, 1435-1451. doi: 10.1080/15548627.2017.1329081

de la Mata, M., Cotan, D., Oropesa-Avila, M., Garrido-Maraver, J., Cordero, M. D., Villanueva Paz, M., et al. (2015). Pharmacological chaperones and coenzyme Q10 treatment improves mutant beta-glucocerebrosidase activity and mitochondrial function in neuronopathic forms of Gaucher disease. Sci. Rep. 5:10903. doi: 10.1038/srep10903

DeBosch, B. J., Heitmeier, M. R., Mayer, A. L., Higgins, C. B., Crowley, J. R., Kraft, T. E., et al. (2016). Trehalose inhibits solute carrier 2A (SLC2A) proteins to induce autophagy and prevent hepatic steatosis. Sci. Signal. 9:ra21. doi: 10.1126/ scisignal.aac5472

Decressac, M., Mattsson, B., Weikop, P., Lundblad, M., Jakobsson, J., and Bjorklund, A. (2013). TFEB-mediated autophagy rescues midbrain dopamine neurons from alpha-synuclein toxicity. Proc. Natl. Acad. Sci. U.S.A. 110, E1817E1826. doi: 10.1073/pnas.1305623110

Desnick, R. J., and Schuchman, E. H. (2012). Enzyme replacement therapy for lysosomal diseases: lessons from 20 years of experience and remaining challenges. Annu. Rev. Genomics Hum. Genet. 13, 307-335. doi: 10.1146/ annurev-genom-090711-163739

Du, J., Liang, Y., Xu, F., Sun, B., and Wang, Z. (2013). Trehalose rescues Alzheimer's disease phenotypes in APP/PS1 transgenic mice. J. Pharm. Pharmacol. 65, 1753-1756. doi: 10.1111/jphp.12108

Du, T. T., Wang, L., Duan, C. L., Lu, L. L., Zhang, J. L., Gao, G., et al. (2015). GBA deficiency promotes SNCA/alpha-synuclein accumulation through autophagic inhibition by inactivated PPP2A. Autophagy 11, 1803-1820. doi: 10.1080/ 15548627.2015.1086055

Duran, J., Gruart, A., Garcia-Rocha, M., Delgado-Garcia, J. M., and Guinovart, J. J. (2014). Glycogen accumulation underlies neurodegeneration and autophagy impairment in Lafora disease. Hum. Mol. Genet. 23, 3147-3156. doi: 10.1093/ hmg/ddu024

Fang, E. F., Hou, Y., Palikaras, K., Adriaanse, B. A., Kerr, J. S., Yang, B., et al. (2019). Mitophagy inhibits amyloid-beta and Tau pathology and reverses cognitive deficits in models of Alzheimer's disease. Nat. Neurosci. 22, 401-412. doi: 10. 1038/s41593-018-0332-9

Farah, B. L., Landau, D. J., Sinha, R. A., Brooks, E. D., Wu, Y., Fung, S. Y. S., et al. (2016). Induction of autophagy improves hepatic lipid metabolism in glucose6-phosphatase deficiency. J. Hepatol. 64, 370-379. doi: 10.1016/j.jhep.2015. 10.008 
Farah, B. L., Landau, D. J., Wu, Y., Sinha, R. A., Loh, A., Bay, B. H., et al. (2017). Renal endoplasmic reticulum stress is coupled to impaired autophagy in a mouse model of GSD Ia. Mol. Genet. Metab. 122, 95-98. doi: 10.1016/j.ymgme. 2017.08.013

Farfel-Becker, T., Vitner, E. B., Kelly, S. L., Bame, J. R., Duan, J., Shinder, V., et al. (2014). Neuronal accumulation of glucosylceramide in a mouse model of neuronopathic Gaucher disease leads to neurodegeneration. Hum. Mol. Genet. 23, 843-854. doi: 10.1093/hmg/ddt468

Filimonenko, M., Isakson, P., Finley, K. D., Anderson, M., Jeong, H., Melia, T. J., et al. (2010). The selective macroautophagic degradation of aggregated proteins requires the PI3P-binding protein Alfy. Mol. Cell 38, 265-279. doi: 10.1016/j. molcel.2010.04.007

Fraldi, A., Annunziata, F., Lombardi, A., Kaiser, H. J., Medina, D. L., Spampanato, C., et al. (2010). Lysosomal fusion and SNARE function are impaired by cholesterol accumulation in lysosomal storage disorders. EMBO J. 29, 36073620. doi: 10.1038/emboj.2010.237

Fu, Y., Wu, P., Pan, Y., Sun, X., Yang, H., Difiglia, M., et al. (2017). A toxic mutant huntingtin species is resistant to selective autophagy. Nat. Chem. Biol. 13, 1152-1154. doi: 10.1038/nchembio.2461

Fukuda, T., Ahearn, M., Roberts, A., Mattaliano, R. J., Zaal, K., Ralston, E., et al. (2006a). Autophagy and mistargeting of therapeutic enzyme in skeletal muscle in Pompe disease. Mol. Ther. 14, 831-839. doi: 10.1016/j.ymthe.2006. 08.009

Fukuda, T., Ewan, L., Bauer, M., Mattaliano, R. J., Zaal, K., Ralston, E., et al. (2006b). Dysfunction of endocytic and autophagic pathways in a lysosomal storage disease. Ann. Neurol. 59, 700-708. doi: 10.1002/ana.20807

Garyali, P., Siwach, P., Singh, P. K., Puri, R., Mittal, S., Sengupta, S., et al. (2009). The malin-laforin complex suppresses the cellular toxicity of misfolded proteins by promoting their degradation through the ubiquitin-proteasome system. Hum. Mol. Genet. 18, 688-700. doi: 10.1093/hmg/ddn398

Gatica, D., Lahiri, V., and Klionsky, D. J. (2018). Cargo recognition and degradation by selective autophagy. Nat. Cell Biol. 20, 233-242. doi: 10.1038/ s41556-018-0037-z

Gayarre, J., Duran-Trio, L., Criado Garcia, O., Aguado, C., Juana-Lopez, L., Crespo, I., et al. (2014). The phosphatase activity of laforin is dispensable to rescue Epm2a-/- mice from Lafora disease. Brain 137(Pt 3), 806-818. doi: 10.1093/ brain/awt353

Geisler, S., Holmstrom, K. M., Treis, A., Skujat, D., Weber, S. S., Fiesel, F. C., et al. (2010). The PINK1/Parkin-mediated mitophagy is compromised by PDassociated mutations. Autophagy 6, 871-878. doi: 10.4161/auto.6.7.13286

Germain, D. P. (2010). Fabry disease. Orphanet J. Rare Dis. 5:30. doi: 10.1186/17501172-5-30

Green, D. R., and Levine, B. (2014). To be or not to be? How selective autophagy and cell death govern cell fate. Cell 157, 65-75. doi: 10.1016/j.cell.2014.02.049

Grumati, P., and Dikic, I. (2018). Ubiquitin signaling and autophagy. J. Biol. Chem. 293, 5404-5413. doi: 10.1074/jbc.TM117.000117

Guo, H., Zhao, M., Qiu, X., Deis, J. A., Huang, H., Tang, Q. Q., et al. (2016). Niemann-Pick type C2 deficiency impairs autophagy-lysosomal activity, mitochondrial function, and TLR signaling in adipocytes. J. Lipid Res. 57, 1644-1658. doi: 10.1194/jlr.M066522

Hara, T., Nakamura, K., Matsui, M., Yamamoto, A., Nakahara, Y., SuzukiMigishima, R., et al. (2006). Suppression of basal autophagy in neural cells causes neurodegenerative disease in mice. Nature 441, 885-889. doi: 10.1038/ nature 04724

Hebron, M. L., Lonskaya, I., Olopade, P., Selby, S. T., Pagan, F., and Moussa, C. E. (2014). Tyrosine kinase inhibition regulates early systemic immune changes and modulates the neuroimmune response in alpha-synucleinopathy. J. Clin. Cell. Immunol. 5:259. doi: 10.4172/2155-9899.1000259

Hosseinpour-Moghaddam, K., Caraglia, M., and Sahebkar, A. (2018). Autophagy induction by trehalose: molecular mechanisms and therapeutic impacts. J. Cell. Physiol. 233, 6524-6543. doi: 10.1002/jcp.26583

Jiang, P., and Mizushima, N. (2014). Autophagy and human diseases. Cell Res. 24, 69-79. doi: 10.1038/cr.2013.161

Jiang, S., Wells, C. D., and Roach, P. J. (2011). Starch-binding domain-containing protein 1 (Stbd1) and glycogen metabolism: identification of the Atg8 family interacting motif (AIM) in Stbd1 required for interaction with GABARAPL1. Biochem. Biophys. Res. Commun. 413, 420-425. doi: 10.1016/j.bbrc.2011. 08.106
Jiang, T., Yu, J. T., Zhu, X. C., Tan, M. S., Wang, H. F., Cao, L., et al. (2014a). Temsirolimus promotes autophagic clearance of amyloid-beta and provides protective effects in cellular and animal models of Alzheimer's disease. Pharmacol. Res. 81, 54-63. doi: 10.1016/j.phrs.2014.02.008

Jiang, T., Yu, J. T., Zhu, X. C., Zhang, Q. Q., Cao, L., Wang, H. F., et al. (2014b). Temsirolimus attenuates tauopathy in vitro and in vivo by targeting Tau hyperphosphorylation and autophagic clearance. Neuropharmacology 85, 121-130. doi: 10.1016/j.neuropharm.2014.05.032

Jiao, M., Ren, F., Zhou, L., Zhang, X., Zhang, L., Wen, T., et al. (2014). Peroxisome proliferator-activated receptor alpha activation attenuates the inflammatory response to protect the liver from acute failure by promoting the autophagy pathway. Cell Death Dis. 5:e1397. doi: 10.1038/cddis.2014.361

Karabiyik, C., Lee, M. J., and Rubinsztein, D. C. (2017). Autophagy impairment in Parkinson's disease. Essays Biochem. 61, 711-720. doi: 10.1042/EBC20170023

Karten, B., Peake, K. B., and Vance, J. E. (2009). Mechanisms and consequences of impaired lipid trafficking in Niemann-Pick type C1-deficient mammalian cells. Biochim. Biophys. Acta 1791, 659-670. doi: 10.1016/j.bbalip.2009. 01.025

Kegel, K. B., Kim, M., Sapp, E., McIntyre, C., Castano, J. G., Aronin, N., et al. (2000). Huntingtin expression stimulates endosomal-lysosomal activity, endosome tubulation, and autophagy. J. Neurosci. 20, 7268-7278. doi: 10.1523/jneurosci. 20-19-07268.2000

Kerr, J. S., Adriaanse, B. A., Greig, N. H., Mattson, M. P., Cader, M. Z., Bohr, V. A., et al. (2017). Mitophagy and Alzheimer's disease: cellular and molecular mechanisms. Trends Neurosci. 40, 151-166. doi: 10.1016/j.tins.2017.01.002

Kim, Y. C., and Guan, K. L. (2015). mTOR: a pharmacologic target for autophagy regulation. J. Clin. Invest. 125, 25-32. doi: 10.1172/JCI73939

Kinghorn, K. J., Gronke, S., Castillo-Quan, J. I., Woodling, N. S., Li, L., Sirka, E., et al. (2016). A Drosophila model of neuronopathic gaucher disease demonstrates lysosomal-autophagic defects and altered mTOR signalling and is functionally rescued by rapamycin. J. Neurosci. 36, 11654-11670. doi: 10.1523/ JNEUROSCI.4527-15.2016

Kirkin, V., Lamark, T., Sou, Y. S., Bjorkoy, G., Nunn, J. L., Bruun, J. A., et al. (2009). A role for NBR1 in autophagosomal degradation of ubiquitinated substrates. Mol. Cell 33, 505-516. doi: 10.1016/j.molcel.2009.01.020

Komatsu, M., Waguri, S., Chiba, T., Murata, S., Iwata, J., Tanida, I., et al. (2006). Loss of autophagy in the central nervous system causes neurodegeneration in mice. Nature 441, 880-884. doi: 10.1038/nature04723

Korac, J., Schaeffer, V., Kovacevic, I., Clement, A. M., Jungblut, B., Behl, C., et al. (2013). Ubiquitin-independent function of optineurin in autophagic clearance of protein aggregates. J. Cell Sci. 126(Pt 2), 580-592. doi: 10.1242/jcs.114926

Kovacs, T., Billes, V., Komlos, M., Hotzi, B., Manzeger, A., Tarnoci, A., et al. (2017). The small molecule AUTEN-99 (autophagy enhancer-99) prevents the progression of neurodegenerative symptoms. Sci. Rep. 7:42014. doi: 10.1038/ srep42014

Ktistakis, N. T., and Tooze, S. A. (2016). Digesting the expanding mechanisms of autophagy. Trends Cell Biol. 26, 624-635. doi: 10.1016/j.tcb.2016.03.006

Kuo, S. Y., Castoreno, A. B., Aldrich, L. N., Lassen, K. G., Goel, G., Dancik, V., et al. (2015). Small-molecule enhancers of autophagy modulate cellular disease phenotypes suggested by human genetics. Proc. Natl. Acad. Sci. U.S.A. 112, E4281-E4287. doi: 10.1073/pnas.1512289112

Kwon, H. J., Abi-Mosleh, L., Wang, M. L., Deisenhofer, J., Goldstein, J. L., Brown, M. S., et al. (2009). Structure of N-terminal domain of NPC1 reveals distinct subdomains for binding and transfer of cholesterol. Cell 137, 1213-1224. doi: 10.1016/j.cell.2009.03.049

Lahuerta, M., Aguado, C., Sanchez-Martin, P., Sanz, P., and Knecht, E. (2018). Degradation of altered mitochondria by autophagy is impaired in Lafora disease. FEBS J. 285, 2071-2090. doi: 10.1111/febs.14468

Lee, H., Lee, J. K., Park, M. H., Hong, Y. R., Marti, H. H., Kim, H., et al. (2014). Pathological roles of the VEGF/SphK pathway in Niemann-Pick type C neurons. Nat. Commun. 5:5514. doi: 10.1038/ncomms6514

Lee, J. M., Wagner, M., Xiao, R., Kim, K. H., Feng, D., Lazar, M. A., et al. (2014). Nutrient-sensing nuclear receptors coordinate autophagy. Nature 516, 112-115. doi: 10.1038/nature13961

Lee, J. H., Yu, W. H., Kumar, A., Lee, S., Mohan, P. S., Peterhoff, C. M., et al. (2010). Lysosomal proteolysis and autophagy require presenilin 1 and are disrupted by Alzheimer-related PS1 mutations. Cell 141, 1146-1158. doi: 10.1016/j.cell.2010. 05.008 
Levine, B., Packer, M., and Codogno, P. (2015). Development of autophagy inducers in clinical medicine. J. Clin. Invest. 125, 14-24. doi: 10.1172/JCI73938

Li, H., Ham, A., Ma, T. C., Kuo, S. H., Kanter, E., Kim, D., et al. (2019). Mitochondrial dysfunction and mitophagy defect triggered by heterozygous GBA mutations. Autophagy 15, 113-130. doi: 10.1080/15548627.2018.1509818

Liebau, M. C., Braun, F., Hopker, K., Weitbrecht, C., Bartels, V., Muller, R. U., et al. (2013). Dysregulated autophagy contributes to podocyte damage in Fabry's disease. PLoS One 8:e63506. doi: 10.1371/journal.pone.0063506

Lim, J. A., Li, L., Kakhlon, O., Myerowitz, R., and Raben, N. (2015). Defects in calcium homeostasis and mitochondria can be reversed in Pompe disease. Autophagy 11, 385-402. doi: 10.1080/15548627.2015.1009779

Lim, J. A., Li, L., Shirihai, O. S., Trudeau, K. M., Puertollano, R., and Raben, N. (2017). Modulation of mTOR signaling as a strategy for the treatment of Pompe disease. EMBO Mol. Med. 9, 353-370. doi: 10.15252/emmm.201606547

Lin, A. L., Jahrling, J. B., Zhang, W., DeRosa, N., Bakshi, V., Romero, P., et al. (2017). Rapamycin rescues vascular, metabolic and learning deficits in apolipoprotein E4 transgenic mice with pre-symptomatic Alzheimer's disease. J. Cereb. Blood Flow Metab. 37, 217-226. doi: 10.1177/0271678X15621575

Liu, J., Liu, W., Lu, Y., Tian, H., Duan, C., Lu, L., et al. (2018). Piperlongumine restores the balance of autophagy and apoptosis by increasing BCL2 phosphorylation in rotenone-induced Parkinson disease models. Autophagy 14, 845-861. doi: 10.1080/15548627.2017.1390636

Liu, K., Shi, N., Sun, Y., Zhang, T., and Sun, X. (2013). Therapeutic effects of rapamycin on MPTP-induced Parkinsonism in mice. Neurochem. Res. 38, 201-207. doi: 10.1007/s11064-012-0909-8

Lloyd-Evans, E., Morgan, A. J., He, X., Smith, D. A., Elliot-Smith, E., Sillence, D. J., et al. (2008). Niemann-Pick disease type $\mathrm{C} 1$ is a sphingosine storage disease that causes deregulation of lysosomal calcium. Nat. Med. 14, 1247-1255. doi: $10.1038 / \mathrm{nm} .1876$

Lu, K., Psakhye, I., and Jentsch, S. (2014). A new class of ubiquitin-Atg8 receptors involved in selective autophagy and polyQ protein clearance. Autophagy 10, 2381-2382. doi: 10.4161/15548627.2014.981919

Maetzel, D., Sarkar, S., Wang, H., Abi-Mosleh, L., Xu, P., Cheng, A. W., et al. (2014). Genetic and chemical correction of cholesterol accumulation and impaired autophagy in hepatic and neural cells derived from Niemann-Pick Type C patient-specific iPS cells. Stem Cell Rep. 2, 866-880. doi: 10.1016/j.stemcr.2014. 03.014

Magalhaes, J., Gegg, M. E., Migdalska-Richards, A., Doherty, M. K., Whitfield, P. D., and Schapira, A. H. (2016). Autophagic lysosome reformation dysfunction in glucocerebrosidase deficient cells: relevance to Parkinson disease. Hum. Mol. Genet. 25, 3432-3445. doi: 10.1093/hmg/ddw185

Majid, T., Ali, Y. O., Venkitaramani, D. V., Jang, M. K., Lu, H. C., and Pautler, R. G. (2014). In vivo axonal transport deficits in a mouse model of frontotemporal dementia. Neuroimage Clin. 4, 711-717. doi: 10.1016/j.nicl.2014. 02.005

Majumder, S., Richardson, A., Strong, R., and Oddo, S. (2011). Inducing autophagy by rapamycin before, but not after, the formation of plaques and tangles ameliorates cognitive deficits. PLoS One 6:e25416. doi: 10.1371/journal.pone. 0025416

Malagelada, C., Jin, Z. H., Jackson-Lewis, V., Przedborski, S., and Greene, L. A. (2010). Rapamycin protects against neuron death in in vitro and in vivo models of Parkinson's disease. J. Neurosci. 30, 1166-1175. doi: 10.1523/JNEUROSCI. 3944-09.2010

Manzoni, C., and Lewis, P. A. (2017). LRRK2 and autophagy. Adv. Neurobiol. 14, 89-105. doi: 10.1007/978-3-319-49969-7_5

Marino, G., Pietrocola, F., Eisenberg, T., Kong, Y., Malik, S. A., Andryushkova, A., et al. (2014). Regulation of autophagy by cytosolic acetyl-coenzyme A. Mol. Cell 53, 710-725. doi: 10.1016/j.molcel.2014.01.016

Martina, J. A., Diab, H. I., Lishu, L., Jeong, A. L., Patange, S., Raben, N., et al. (2014). The nutrient-responsive transcription factor TFE3 promotes autophagy, lysosomal biogenesis, and clearance of cellular debris. Sci. Signal. 7:ra9. doi: 10.1126/scisignal.2004754

Martinez-Vicente, M., Talloczy, Z., Kaushik, S., Massey, A. C., Mazzulli, J., Mosharov, E. V., et al. (2008). Dopamine-modified alpha-synuclein blocks chaperone-mediated autophagy. J. Clin. Invest. 118, 777-788. doi: 10.1172/ JCI32806

Martinez-Vicente, M., Talloczy, Z., Wong, E., Tang, G., Koga, H., Kaushik, S., et al. (2010). Cargo recognition failure is responsible for inefficient autophagy in Huntington's disease. Nat. Neurosci. 13, 567-576. doi: 10.1038/nn. 2528

Masini, D., Bonito-Oliva, A., Bertho, M., and Fisone, G. (2018). Inhibition of mTORC1 signaling reverts cognitive and affective deficits in a mouse model of Parkinson's disease. Front. Neurol. 9:208. doi: 10.3389/fneur.2018. 00208

Mazzulli, J. R., Xu, Y. H., Sun, Y., Knight, A. L., McLean, P. J., Caldwell, G. A., et al. (2011). Gaucher disease glucocerebrosidase and alpha-synuclein form a bidirectional pathogenic loop in synucleinopathies. Cell 146, 37-52. doi: 10. 1016/j.cell.2011.06.001

Medina, D. L., Di Paola, S., Peluso, I., Armani, A., De Stefani, D., Venditti, R., et al. (2015). Lysosomal calcium signalling regulates autophagy through calcineurin and TFEB. Nat. Cell Biol. 17, 288-299. doi: 10.1038/ncb3114

Medina, D. L., Fraldi, A., Bouche, V., Annunziata, F., Mansueto, G., Spampanato, C., et al. (2011). Transcriptional activation of lysosomal exocytosis promotes cellular clearance. Dev. Cell 21, 421-430. doi: 10.1016/j.devcel.2011.07.016

Meijer, A. J., Lorin, S., Blommaart, E. F., and Codogno, P. (2015). Regulation of autophagy by amino acids and MTOR-dependent signal transduction. Amino Acids 47, 2037-2063. doi: 10.1007/s00726-014-1765-4

Meng, X., Luo, Y., Liang, T., Wang, M., Zhao, J., Sun, G., et al. (2016). Gypenoside XVII enhances lysosome biogenesis and autophagy flux and accelerates autophagic clearance of amyloid-beta through TFEB activation. J. Alzheimers Dis. 52, 1135-1150. doi: 10.3233/JAD- 160096

Menzies, F. M., Fleming, A., Caricasole, A., Bento, C. F., Andrews, S. P., Ashkenazi, A., et al. (2017). Autophagy and neurodegeneration: pathogenic mechanisms and therapeutic opportunities. Neuron 93, 1015-1034. doi: 10.1016/j.neuron. 2017.01.022

Menzies, F. M., Garcia-Arencibia, M., Imarisio, S., O’Sullivan, N. C., Ricketts, T., Kent, B. A., et al. (2015). Calpain inhibition mediates autophagy-dependent protection against polyglutamine toxicity. Cell Death Differ. 22, 433-444. doi: 10.1038/cdd.2014.151

Mizushima, N. (2018). A brief history of autophagy from cell biology to physiology and disease. Nat. Cell Biol. 20, 521-527. doi: 10.1038/s41556-018-0092-5

Mizushima, N., Yoshimori, T., and Ohsumi, Y. (2011). The role of Atg proteins in autophagosome formation. Annu. Rev. Cell Dev. Biol. 27, 107-132. doi: 10.1146/annurev-cellbio-092910-154005

Nakamura, S., and Yoshimori, T. (2017). New insights into autophagosomelysosome fusion. J. Cell Sci. 130, 1209-1216. doi: 10.1242/jcs.196352

Narendra, D. P., Jin, S. M., Tanaka, A., Suen, D. F., Gautier, C. A., Shen, J., et al. (2010). PINK1 is selectively stabilized on impaired mitochondria to activate Parkin. PLoS Biol. 8:e1000298. doi: 10.1371/journal.pbio.1000298

Nascimbeni, A. C., Fanin, M., Masiero, E., Angelini, C., and Sandri, M. (2012). The role of autophagy in the pathogenesis of glycogen storage disease type II (GSDII). Cell Death Differ. 19, 1698-1708. doi: 10.1038/cdd.2012.52

Nascimbeni, A. C., Fanin, M., Tasca, E., Angelini, C., and Sandri, M. (2015). Impaired autophagy affects acid alpha-glucosidase processing and enzyme replacement therapy efficacy in late-onset glycogen storage disease type II. Neuropathol. Appl. Neurobiol. 41, 672-675. doi: 10.1111/nan.12214

Nelson, M. P., Tse, T. E., O'Quinn, D. B., Percival, S. M., Jaimes, E. A., Warnock, D. G., et al. (2014). Autophagy-lysosome pathway associated neuropathology and axonal degeneration in the brains of alpha-galactosidase A-deficient mice. Acta Neuropathol. Commun. 2:20. doi: 10.1186/2051-5960-2-20

Ng, F., and Tang, B. L. (2013). Sirtuins' modulation of autophagy. J. Cell Physiol. 228, 2262-2270. doi: $10.1002 /$ jcp.24399

Nilsson, P., Loganathan, K., Sekiguchi, M., Matsuba, Y., Hui, K., Tsubuki, S., et al. (2013). Abeta secretion and plaque formation depend on autophagy. Cell Rep. 5, 61-69. doi: 10.1016/j.celrep.2013.08.042

Nitschke, F., Ahonen, S. J., Nitschke, S., Mitra, S., and Minassian, B. A. (2018). Lafora disease - from pathogenesis to treatment strategies. Nat. Rev. Neurol. 14, 606-617. doi: 10.1038/s41582-018-0057-0

Nixon, R. A. (2013). The role of autophagy in neurodegenerative disease. Nat. Med. 19, 983-997. doi: 10.1038/nm.3232

Ochaba, J., Lukacsovich, T., Csikos, G., Zheng, S., Margulis, J., Salazar, L., et al. (2014). Potential function for the Huntingtin protein as a scaffold for selective autophagy. Proc. Natl. Acad. Sci. U.S.A. 111, 16889-16894. doi: 10.1073/pnas. 1420103111

Ordonez, M. P., Roberts, E. A., Kidwell, C. U., Yuan, S. H., Plaisted, W. C., and Goldstein, L. S. (2012). Disruption and therapeutic rescue of autophagy in 
a human neuronal model of Niemann Pick type C1. Hum. Mol. Genet. 21, 2651-2662. doi: 10.1093/hmg/dds090

Osellame, L. D., Rahim, A. A., Hargreaves, I. P., Gegg, M. E., Richard-Londt, A., Brandner, S., et al. (2013). Mitochondria and quality control defects in a mouse model of Gaucher disease-links to Parkinson's disease. Cell Metab. 17, 941-953. doi: 10.1016/j.cmet.2013.04.014

Ozcelik, S., Fraser, G., Castets, P., Schaeffer, V., Skachokova, Z., Breu, K., et al. (2013). Rapamycin attenuates the progression of tau pathology in P301S tau transgenic mice. PLoS One 8:e62459. doi: 10.1371/journal.pone.0062459

Panda, P. K., Fahrner, A., Vats, S., Seranova, E., Sharma, V., Chipara, M., et al. (2019). Chemical screening approaches enabling drug discovery of autophagy modulators for biomedical applications in human diseases. Front. Cell. Dev. Biol. 7:38. doi: 10.3389/fcell.2019.00038

Pankiv, S., Clausen, T. H., Lamark, T., Brech, A., Bruun, J. A., Outzen, H., et al. (2007). p62/SQSTM1 binds directly to Atg8/LC3 to facilitate degradation of ubiquitinated protein aggregates by autophagy. J. Biol. Chem. 282, 2413124145. doi: 10.1074/jbc.M702824200

Peake, K. B., and Vance, J. E. (2012). Normalization of cholesterol homeostasis by 2-hydroxypropyl-beta-cyclodextrin in neurons and glia from Niemann-Pick C1 (NPC1)-deficient mice. J. Biol. Chem. 287, 9290-9298. doi: 10.1074/jbc.M111. 326405

Petersen, A., Larsen, K. E., Behr, G. G., Romero, N., Przedborski, S., Brundin, P., et al. (2001). Expanded CAG repeats in exon 1 of the Huntington's disease gene stimulate dopamine-mediated striatal neuron autophagy and degeneration. Hum. Mol. Genet. 10, 1243-1254. doi: 10.1093/hmg/10.12.1243

Pickford, F., Masliah, E., Britschgi, M., Lucin, K., Narasimhan, R., Jaeger, P. A., et al. (2008). The autophagy-related protein beclin 1 shows reduced expression in early Alzheimer disease and regulates amyloid beta accumulation in mice. J. Clin. Invest. 118, 2190-2199. doi: 10.1172/JCI33585

Pickrell, A. M., and Youle, R. J. (2015). The roles of PINK1, Parkin, and mitochondrial fidelity in Parkinson's disease. Neuron 85, 257-273. doi: 10.1016/ j.neuron.2014.12.007

Piras, A., Collin, L., Gruninger, F., Graff, C., and Ronnback, A. (2016). Autophagic and lysosomal defects in human tauopathies: analysis of post-mortem brain from patients with familial Alzheimer disease, corticobasal degeneration and progressive supranuclear palsy. Acta Neuropathol. Commun. 4:22. doi: 10.1186/ s40478-016-0292-9

Polito, V. A., Li, H., Martini-Stoica, H., Wang, B., Yang, L., Xu, Y., et al. (2014). Selective clearance of aberrant tau proteins and rescue of neurotoxicity by transcription factor EB. EMBO Mol. Med. 6, 1142-1160. doi: 10.15252/emmm. 201303671

Portbury, S. D., Hare, D. J., Sgambelloni, C., Perronnes, K., Portbury, A. J., Finkelstein, D. I., et al. (2017). Trehalose improves cognition in the transgenic Tg2576 mouse model of Alzheimer's disease. J. Alzheimers Dis. 60, 549-560. doi: 10.3233/JAD- 170322

Pupyshev, A. B., Tikhonova, M. A., Akopyan, A. A., Tenditnik, M. V., Dubrovina, N. I., and Korolenko, T. A. (2019). Therapeutic activation of autophagy by combined treatment with rapamycin and trehalose in a mouse MPTP-induced model of Parkinson's disease. Pharmacol. Biochem. Behav. 177, 1-11. doi: 10. 1016/j.pbb.2018.12.005

Raben, N., Hill, V., Shea, L., Takikita, S., Baum, R., Mizushima, N., et al. (2008). Suppression of autophagy in skeletal muscle uncovers the accumulation of ubiquitinated proteins and their potential role in muscle damage in Pompe disease. Hum. Mol. Genet. 17, 3897-3908. doi: 10.1093/hmg/ddn292

Raben, N., Plotz, P., and Byrne, B. J. (2002). Acid alpha-glucosidase deficiency (glycogenosis type II, Pompe disease). Curr. Mol. Med. 2, 145-166. doi: 10. 2174/1566524024605789

Ravikumar, B., Acevedo-Arozena, A., Imarisio, S., Berger, Z., Vacher, C., O'Kane, C. J., et al. (2005). Dynein mutations impair autophagic clearance of aggregateprone proteins. Nat. Genet. 37, 771-776. doi: 10.1038/ng1591

Ravikumar, B., Duden, R., and Rubinsztein, D. C. (2002). Aggregate-prone proteins with polyglutamine and polyalanine expansions are degraded by autophagy. Hum. Mol. Genet. 11, 1107-1117. doi: 10.1093/hmg/11.9.1107

Ravikumar, B., Vacher, C., Berger, Z., Davies, J. E., Luo, S., Oroz, L. G., et al. (2004). Inhibition of mTOR induces autophagy and reduces toxicity of polyglutamine expansions in fly and mouse models of Huntington disease. Nat. Genet. 36, 585-595. doi: $10.1038 / \mathrm{ng} 1362$
Reggiori, F., and Ungermann, C. (2017). Autophagosome maturation and fusion. J. Mol. Biol. 429, 486-496. doi: 10.1016/j.jmb.2017.01.002

Rodriguez-Navarro, J. A., Rodriguez, L., Casarejos, M. J., Solano, R. M., Gomez, A., Perucho, J., et al. (2010). Trehalose ameliorates dopaminergic and tau pathology in Parkin deleted/tau overexpressing mice through autophagy activation. Neurobiol. Dis. 39, 423-438. doi: 10.1016/j.nbd.2010.05.014

Rohn, T. T., Wirawan, E., Brown, R. J., Harris, J. R., Masliah, E., and Vandenabeele, P. (2011). Depletion of beclin-1 due to proteolytic cleavage by caspases in the Alzheimer's disease brain. Neurobiol. Dis. 43, 68-78. doi: 10.1016/j.nbd.2010. 11.003

Roma-Mateo, C., Aguado, C., Garcia-Gimenez, J. L., Ibanez-Cabellos, J. S., SecoCervera, M., Pallardo, F. V., et al. (2015). Increased oxidative stress and impaired antioxidant response in Lafora disease. Mol. Neurobiol. 51, 932-946. doi: 10.1007/s12035-014-8747-0

Rose, C., Menzies, F. M., Renna, M., Acevedo-Arozena, A., Corrochano, S., Sadiq, O., et al. (2010). Rilmenidine attenuates toxicity of polyglutamine expansions in a mouse model of Huntington's disease. Hum. Mol. Genet. 19, 2144-2153. doi: $10.1093 / \mathrm{hmg} / \mathrm{ddq} 093$

Rubinsztein, D. C., Codogno, P., and Levine, B. (2012). Autophagy modulation as a potential therapeutic target for diverse diseases. Nat. Rev. Drug Discov. 11, 709-730. doi: $10.1038 / \mathrm{nrd} 3802$

Rui, Y. N., Xu, Z., Patel, B., Chen, Z., Chen, D., Tito, A., et al. (2015). Huntingtin functions as a scaffold for selective macroautophagy. Nat. Cell Biol. 17, 262-275. doi: $10.1038 / \mathrm{ncb} 3101$

Russell, R. C., Yuan, H. X., and Guan, K. L. (2014). Autophagy regulation by nutrient signaling. Cell Res. 24, 42-57. doi: 10.1038/cr.20 13.166

Ryu, Y. K., Park, H. Y., Go, J., Choi, D. H., Kim, Y. H., Hwang, J. H., et al. (2018). Metformin inhibits the development of L-DOPA-induced dyskinesia in a murine model of Parkinson's disease. Mol. Neurobiol. 55, 5715-5726. doi: 10.1007/s12035-017-0752-7

Santini, E., Heiman, M., Greengard, P., Valjent, E., and Fisone, G. (2009). Inhibition of mTOR signaling in Parkinson's disease prevents L-DOPA-induced dyskinesia. Sci. Signal. 2:ra36. doi: 10.1126/scisignal.2000308

Sarkar, S. (2013). Regulation of autophagy by mTOR-dependent and mTORindependent pathways: autophagy dysfunction in neurodegenerative diseases and therapeutic application of autophagy enhancers. Biochem. Soc. Trans. 41, 1103-1130. doi: 10.1042/BST20130134

Sarkar, S., Carroll, B., Buganim, Y., Maetzel, D., Ng, A. H., Cassady, J. P., et al. (2013). Impaired autophagy in the lipid-storage disorder NiemannPick type C1 disease. Cell Rep. 5, 1302-1315. doi: 10.1016/j.celrep.2013. 10.042

Sarkar, S., Davies, J. E., Huang, Z., Tunnacliffe, A., and Rubinsztein, D. C. (2007a). Trehalose, a novel mTOR-independent autophagy enhancer, accelerates the clearance of mutant huntingtin and alpha-synuclein. J. Biol. Chem. 282, 56415652. doi: 10.1074/jbc.M609532200

Sarkar, S., Perlstein, E. O., Imarisio, S., Pineau, S., Cordenier, A., Maglathlin, R. L., et al. (2007b). Small molecules enhance autophagy and reduce toxicity in Huntington's disease models. Nat. Chem. Biol. 3, 331-338. doi: 10.1038/ nchembio 883

Sarkar, S., Floto, R. A., Berger, Z., Imarisio, S., Cordenier, A., Pasco, M., et al. (2005). Lithium induces autophagy by inhibiting inositol monophosphatase. J. Cell Biol. 170, 1101-1111. doi: 10.1083/jcb.200504035

Sarkar, S., Korolchuk, V. I., Renna, M., Imarisio, S., Fleming, A., Williams, A., et al. (2011). Complex inhibitory effects of nitric oxide on autophagy. Mol. Cell 43, 19-32. doi: 10.1016/j.molcel.2011.04.029

Sarkar, S., Krishna, G., Imarisio, S., Saiki, S., O’Kane, C. J., and Rubinsztein, D. C. (2008). A rational mechanism for combination treatment of Huntington's disease using lithium and rapamycin. Hum. Mol. Genet. 17, 170-178. doi: 10. 1093/hmg/ddm294

Sarkar, S., Ravikumar, B., Floto, R. A., and Rubinsztein, D. C. (2009). Rapamycin and mTOR-independent autophagy inducers ameliorate toxicity of polyglutamine-expanded huntingtin and related proteinopathies. Cell Death Differ. 16, 46-56. doi: 10.1038/cdd.2008.110

Sarkar, S., and Rubinsztein, D. C. (2008). Huntington's disease: degradation of mutant huntingtin by autophagy. FEBS J. 275, 4263-4270. doi: 10.1111/j.17424658.2008.06562.x 
Sato, Y., Kobayashi, H., Higuchi, T., Shimada, Y., Ida, H., and Ohashi, T. (2016). TFEB overexpression promotes glycogen clearance of Pompe disease iPSCderived skeletal muscle. Mol. Ther. Methods Clin. Dev. 3:16054. doi: 10.1038/ mtm.2016.54

Schaeffer, V., Lavenir, I., Ozcelik, S., Tolnay, M., Winkler, D. T., and Goedert, M. (2012). Stimulation of autophagy reduces neurodegeneration in a mouse model of human tauopathy. Brain 135(Pt 7), 2169-2177. doi: 10.1093/brain/aws143

Schondorf, D. C., Aureli, M., McAllister, F. E., Hindley, C. J., Mayer, F., Schmid, B., et al. (2014). iPSC-derived neurons from GBA1-associated Parkinson's disease patients show autophagic defects and impaired calcium homeostasis. Nat. Commun. 5:4028. doi: 10.1038/ncomms5028

Schultz, M. L., Krus, K. L., Kaushik, S., Dang, D., Chopra, R., Qi, L., et al. (2018). Coordinate regulation of mutant NPC1 degradation by selective ER autophagy and MARCH6-dependent ERAD. Nat. Commun. 9:3671. doi: 10.1038/s41467018-06115-2

Selkoe, D. J., and Hardy, J. (2016). The amyloid hypothesis of Alzheimer's disease at 25 years. EMBO Mol. Med. 8, 595-608. doi: 10.15252/emmm. 201606210

Seranova, E., Connolly, K. J., Zatyka, M., Rosenstock, T. R., Barrett, T., Tuxworth, R. I., et al. (2017). Dysregulation of autophagy as a common mechanism in lysosomal storage diseases. Essays Biochem. 61, 733-749. doi: 10.1042/ EBC20170055

Settembre, C., Fraldi, A., Medina, D. L., and Ballabio, A. (2013). Signals from the lysosome: a control centre for cellular clearance and energy metabolism. Nat. Rev. Mol. Cell Biol. 14, 283-296. doi: 10.1038/nrm3565

Shoji-Kawata, S., Sumpter, R., Leveno, M., Campbell, G. R., Zou, Z., Kinch, L., et al. (2013). Identification of a candidate therapeutic autophagy-inducing peptide. Nature 494, 201-206. doi: 10.1038/nature11866

Siddiqi, F. H., Menzies, F. M., Lopez, A., Stamatakou, E., Karabiyik, C., Ureshino, R., et al. (2019). Felodipine induces autophagy in mouse brains with pharmacokinetics amenable to repurposing. Nat. Commun. 10:1817. doi: 10.1038/s41467-019-09494-2

Sidransky, E., Nalls, M. A., Aasly, J. O., Aharon-Peretz, J., Annesi, G., Barbosa, E. R., et al. (2009). Multicenter analysis of glucocerebrosidase mutations in Parkinson's disease. N. Engl. J. Med. 361, 1651-1661. doi: 10.1056/ NEJMoa0901281

Siman, R., Cocca, R., and Dong, Y. (2015). The mTOR inhibitor rapamycin mitigates perforant pathway neurodegeneration and synapse loss in a mouse model of early-stage alzheimer-type tauopathy. PLoS One 10:e0142340. doi: 10.1371/journal.pone.0142340

Singh, P. K., Singh, S., and Ganesh, S. (2013). Activation of serum/glucocorticoidinduced kinase 1 (SGK1) underlies increased glycogen levels, mTOR activation, and autophagy defects in Lafora disease. Mol. Biol. Cell 24, 3776-3786. doi: 10.1091/mbc.E13-05-0261

Singh, R., Kaushik, S., Wang, Y., Xiang, Y., Novak, I., Komatsu, M., et al. (2009). Autophagy regulates lipid metabolism. Nature 458, 1131-1135. doi: 10.1038/ nature 07976

Spampanato, C., Feeney, E., Li, L., Cardone, M., Lim, J. A., Annunziata, F., et al. (2013). Transcription factor EB (TFEB) is a new therapeutic target for Pompe disease. EMBO Mol. Med. 5, 691-706. doi: 10.1002/emmm.20120 2176

Spencer, B., Potkar, R., Trejo, M., Rockenstein, E., Patrick, C., Gindi, R., et al. (2009). Beclin 1 gene transfer activates autophagy and ameliorates the neurodegenerative pathology in alpha-synuclein models of Parkinson's and lewy body diseases. J. Neurosci. 29, 13578-13588. doi: 10.1523/JNEUROSCI. 4390-09.2009

Spillantini, M. G., and Goedert, M. (2013). Tau pathology and neurodegeneration. Lancet Neurol. 12, 609-622. doi: 10.1016/s1474-4422(13)70090-5

Spilman, P., Podlutskaya, N., Hart, M. J., Debnath, J., Gorostiza, O., Bredesen, D., et al. (2010). Inhibition of mTOR by rapamycin abolishes cognitive deficits and reduces amyloid-beta levels in a mouse model of Alzheimer's disease. PLoS One 5:e9979. doi: 10.1371/journal.pone.0009979

Steele, J. W., Lachenmayer, M. L., Ju, S., Stock, A., Liken, J., Kim, S. H., et al. (2013). Latrepirdine improves cognition and arrests progression of neuropathology in an Alzheimer's mouse model. Mol. Psychiatry 18, 889-897. doi: 10.1038/mp. 2012.106

Stirnemann, J., Belmatoug, N., Camou, F., Serratrice, C., Froissart, R., Caillaud, C., et al. (2017). A review of gaucher disease pathophysiology, clinical presentation and treatments. Int. J. Mol. Sci. 18:E441. doi: 10.3390/ijms18020441
Stolz, A., Ernst, A., and Dikic, I. (2014). Cargo recognition and trafficking in selective autophagy. Nat. Cell Biol. 16, 495-501. doi: 10.1038/ncb2979

Sun, Y., Liou, B., Ran, H., Skelton, M. R., Williams, M. T., Vorhees, C. V., et al. (2010). Neuronopathic Gaucher disease in the mouse: viable combined selective saposin C deficiency and mutant glucocerebrosidase (V394L) mice with glucosylsphingosine and glucosylceramide accumulation and progressive neurological deficits. Hum. Mol. Genet. 19, 1088-1097. doi: 10.1093/hmg/ ddp580

Suresh, S. N., Chavalmane, A. K., Dj, V., Yarreiphang, H., Rai, S., Paul, A., et al. (2017). A novel autophagy modulator 6-Bio ameliorates SNCA/alpha-synuclein toxicity. Autophagy 13, 1221-1234. doi: 10.1080/15548627.2017.1302045

Takikita, S., Myerowitz, R., Zaal, K., Raben, N., and Plotz, P. H. (2009). Murine muscle cell models for Pompe disease and their use in studying therapeutic approaches. Mol. Genet. Metab. 96, 208-217. doi: 10.1016/j.ymgme.2008.12.012

Tamura, A., and Yui, N. (2015). beta-cyclodextrin-threaded biocleavable polyrotaxanes ameliorate impaired autophagic flux in niemann-pick type C disease. J. Biol. Chem. 290, 9442-9454. doi: 10.1074/jbc.M115.636803

Tanaka, M., Machida, Y., Niu, S., Ikeda, T., Jana, N. R., Doi, H., et al. (2004). Trehalose alleviates polyglutamine-mediated pathology in a mouse model of Huntington disease. Nat. Med. 10, 148-154. doi: 10.1038/nm985

Tanik, S. A., Schultheiss, C. E., Volpicelli-Daley, L. A., Brunden, K. R., and Lee, V. M. (2013). Lewy body-like alpha-synuclein aggregates resist degradation and impair macroautophagy. J. Biol. Chem. 288, 15194-15210. doi: 10.1074/jbc. M113.457408

Tardiff, D. F., Jui, N. T., Khurana, V., Tambe, M. A., Thompson, M. L., Chung, C. Y., et al. (2013). Yeast reveal a "druggable" Rsp5/Nedd4 network that ameliorates alpha-synuclein toxicity in neurons. Science 342, 979-983. doi: 10.1126/science. 1245321

Tatti, M., Motta, M., Di Bartolomeo, S., Scarpa, S., Cianfanelli, V., Cecconi, F., et al. (2012). Reduced cathepsins B and D cause impaired autophagic degradation that can be almost completely restored by overexpression of these two proteases in Sap C-deficient fibroblasts. Hum. Mol. Genet. 21, 5159-5173. doi: 10.1093/ hmg/dds367

Thoreen, C. C., Kang, S. A., Chang, J. W., Liu, Q., Zhang, J., Gao, Y., et al. (2009). An ATP-competitive mammalian target of rapamycin inhibitor reveals rapamycin-resistant functions of mTORC1. J. Biol. Chem. 284, 8023-8032. doi: 10.1074/jbc.M900301200

Tian, Y., Bustos, V., Flajolet, M., and Greengard, P. (2011). A small-molecule enhancer of autophagy decreases levels of Abeta and APP-CTF via Atg5dependent autophagy pathway. FASEB J. 25, 1934-1942. doi: 10.1096/fj.10175158

Tian, Y., Chang, J. C., Fan, E. Y., Flajolet, M., and Greengard, P. (2013). Adaptor complex AP2/PICALM, through interaction with LC3, targets Alzheimer's APP-CTF for terminal degradation via autophagy. Proc. Natl. Acad. Sci. U.S.A. 110, 17071-17076. doi: 10.1073/pnas.1315110110

Tooze, S. A., and Yoshimori, T. (2010). The origin of the autophagosomal membrane. Nat. Cell Biol. 12, 831-835. doi: 10.1038/ncb0910-831

Upadhyay, M., Agarwal, S., Bhadauriya, P., and Ganesh, S. (2017). Loss of laforin or malin results in increased Drpl level and concomitant mitochondrial fragmentation in Lafora disease mouse models. Neurobiol. Dis. 100, 39-51. doi: 10.1016/j.nbd.2017.01.002

Vaccaro, A. M., Motta, M., Tatti, M., Scarpa, S., Masuelli, L., Bhat, M., et al. (2010). Saposin C mutations in Gaucher disease patients resulting in lysosomal lipid accumulation, saposin $\mathrm{C}$ deficiency, but normal prosaposin processing and sorting. Hum. Mol. Genet. 19, 2987-2997. doi: 10.1093/hmg/ddq204

Vanier, M. T. (2010). Niemann-Pick disease type C. Orphanet J. Rare Dis. 5:16. doi: 10.1186/1750-1172-5-16

Vite, C. H., Bagel, J. H., Swain, G. P., Prociuk, M., Sikora, T. U., Stein, V. M., et al. (2015). Intracisternal cyclodextrin prevents cerebellar dysfunction and Purkinje cell death in feline Niemann-Pick type C1 disease. Sci. Transl. Med. 7:276ra26. doi: 10.1126/scitranslmed.3010101

Wang, I. F., Guo, B. S., Liu, Y. C., Wu, C. C., Yang, C. H., Tsai, K. J., et al. (2012). Autophagy activators rescue and alleviate pathogenesis of a mouse model with proteinopathies of the TAR DNA-binding protein 43. Proc. Natl. Acad. Sci. U.S.A. 109, 15024-15029. doi: 10.1073/pnas.1206362109

Wang, Y., Li, L., Hou, C., Lai, Y., Long, J., Liu, J., et al. (2016). SNARE-mediated membrane fusion in autophagy. Semin. Cell Dev. Biol. 60, 97-104. doi: 10.1016/ j.semcdb.2016.07.009 
Wang, Y., Martinez-Vicente, M., Kruger, U., Kaushik, S., Wong, E., Mandelkow, E. M., et al. (2009). Tau fragmentation, aggregation and clearance: the dual role of lysosomal processing. Hum. Mol. Genet. 18, 4153-4170. doi: 10.1093/hmg/ ddp367

Ward, C., Martinez-Lopez, N., Otten, E. G., Carroll, B., Maetzel, D., Singh, R., et al. (2016). Autophagy, lipophagy and lysosomal lipid storage disorders. Biochim. Biophys. Acta 1861, 269-284. doi: 10.1016/j.bbalip.2016.01.006

Waskowicz, L. R., Zhou, J., Landau, D. J., Brooks, E. D., Lim, A., Yavarow, Z. A., et al. (2019). Bezafibrate induces autophagy and improves hepatic lipid metabolism in glycogen storage disease type Ia. Hum. Mol. Genet. 28, 143-154. doi: $10.1093 / \mathrm{hmg} / \mathrm{ddy} 343$

Webb, J. L., Ravikumar, B., Atkins, J., Skepper, J. N., and Rubinsztein, D. C. (2003). Alpha-Synuclein is degraded by both autophagy and the proteasome. J. Biol. Chem. 278, 25009-25013. doi: 10.1074/jbc.M300227200

Williams, A., Sarkar, S., Cuddon, P., Ttofi, E. K., Saiki, S., Siddiqi, F. H., et al. (2008). Novel targets for Huntington's disease in an mTOR-independent autophagy pathway. Nat. Chem. Biol. 4, 295-305. doi: 10.1038/nchembio.79

Winslow, A. R., Chen, C. W., Corrochano, S., Acevedo-Arozena, A., Gordon, D. E., Peden, A. A., et al. (2010). alpha-Synuclein impairs macroautophagy: implications for Parkinson's disease. J. Cell Biol. 190, 1023-1037. doi: 10.1083/ jcb. 201003122

Wolfe, D. M., Lee, J. H., Kumar, A., Lee, S., Orenstein, S. J., and Nixon, R. A. (2013). Autophagy failure in Alzheimer's disease and the role of defective lysosomal acidification. Eur. J. Neurosci. 37, 1949-1961. doi: 10.1111/ejn. 12169

Wong, Y. C., and Holzbaur, E. L. (2014). The regulation of autophagosome dynamics by huntingtin and HAP1 is disrupted by expression of mutant huntingtin, leading to defective cargo degradation. J. Neurosci. 34, 1293-1305. doi: 10.1523/JNEUROSCI.1870-13.2014

Xiao, Q., Yan, P., Ma, X., Liu, H., Perez, R., Zhu, A., et al. (2014). Enhancing astrocytic lysosome biogenesis facilitates Abeta clearance and attenuates amyloid plaque pathogenesis. J. Neurosci. 34, 9607-9620. doi: 10.1523/ JNEUROSCI.3788-13.2014

Yanagisawa, H., Hossain, M. A., Miyajima, T., Nagao, K., Miyashita, T., and Eto, Y. (2019). Dysregulated DNA methylation of GLA gene was associated with dysfunction of autophagy. Mol. Genet. Metab. 126, 460-465. doi: 10.1016/j. ymgme.2019.03.003

Yoon, Y. S., Cho, E. D., Jung Ahn, W., Won Lee, K., Lee, S. J., and Lee, H. J. (2017). Is trehalose an autophagic inducer? Unraveling the roles of non-reducing disaccharides on autophagic flux and alpha-synuclein aggregation. Cell Death Dis. 8:e3091. doi: 10.1038/cddis.2017.501
Youle, R. J., and Narendra, D. P. (2011). Mechanisms of mitophagy. Nat. Rev. Mol. Cell Biol. 12, 9-14. doi: 10.1038/nrm3028

Yu, L., Chen, Y., and Tooze, S. A. (2018). Autophagy pathway: cellular and molecular mechanisms. Autophagy 14, 207-215. doi: 10.1080/15548627.2017. 1378838

Yu, W. H., Cuervo, A. M., Kumar, A., Peterhoff, C. M., Schmidt, S. D., Lee, J. H., et al. (2005). Macroautophagy-a novel Beta-amyloid peptide-generating pathway activated in Alzheimer's disease. J. Cell Biol. 171, 87-98. doi: 10.1083/ jcb. 200505082

Zachari, M., and Ganley, I. G. (2017). The mammalian ULK1 complex and autophagy initiation. Essays Biochem. 61, 585-596. doi: 10.1042/EBC20170021

Zavodszky, E., Seaman, M. N., Moreau, K., Jimenez-Sanchez, M., Breusegem, S. Y., Harbour, M. E., et al. (2014). Mutation in VPS35 associated with Parkinson's disease impairs WASH complex association and inhibits autophagy. Nat. Commun. 5:3828. doi: 10.1038/ncomms4828

Zhang, L., Wang, L., Wang, R., Gao, Y., Che, H., Pan, Y., et al. (2017). Evaluating the effectiveness of GTM-1, rapamycin, and carbamazepine on autophagy and Alzheimer disease. Med. Sci. Monit. 23, 801-808. doi: 10.12659/msm.898679

Zhao, H., Tang, M., Liu, M., and Chen, L. (2018). Glycophagy: an emerging target in pathology. Clin. Chim. Acta 484, 298-303. doi: 10.1016/j.cca.2018. 06.014

Zhu, Y., Zhang, M., Kelly, A. R., and Cheng, A. (2014). The carbohydratebinding domain of overexpressed STBD1 is important for its stability and protein-protein interactions. Biosci. Rep. 34:e00117. doi: 10.1042/BSR20140053

Zirin, J., Nieuwenhuis, J., and Perrimon, N. (2013). Role of autophagy in glycogen breakdown and its relevance to chloroquine myopathy. PLoS Biol. 11:e1001708. doi: 10.1371/journal.pbio.1001708

Zoghbi, H. Y., and Orr, H. T. (2000). Glutamine repeats and neurodegeneration. Annu. Rev. Neurosci. 23, 217-247. doi: 10.1146/annurev.neuro.23.1.217

Conflict of Interest Statement: The authors declare that the research was conducted in the absence of any commercial or financial relationships that could be construed as a potential conflict of interest.

Copyright (c) 2019 Palhegyi, Seranova, Dimova, Hoque and Sarkar. This is an openaccess article distributed under the terms of the Creative Commons Attribution License (CC BY). The use, distribution or reproduction in other forums is permitted, provided the original author(s) and the copyright owner(s) are credited and that the original publication in this journal is cited, in accordance with accepted academic practice. No use, distribution or reproduction is permitted which does not comply with these terms. 